\title{
A Compression Model for Ultimate Postbuckling Shear Strength
}

\author{
Jonathan D. Glassman ${ }^{1}$, Maria E. Moreyra Garlock ${ }^{2}$ \\ ${ }^{1}$ Associate, Exponent Failure Analysis Associates, jglassman@exponent.com \\ ${ }^{2}$ Associate Professor, Department of Civil and Environmental Engineering, Princeton University, \\ mgarlock@princeton.edu
}

Abstract: Tension field theory has traditionally been used to determine the ultimate postbuckling shear strength of steel plates. More than a dozen theories have been proposed in the last nine decades to describe and predict this phenomenon, and all are based on the tensile response of the web plate, referred to as tension field action. Alternatively, in this paper a compression approach for determining the ultimate postbuckling shear strength is studied. First, an experimentally-validated finite element model is used to examine the mechanics of plate shear buckling. The response is shown to be similar to axially compressed plates, but in this case the axial compression is acting on a diagonal. Then a physical model and formulation based on the compressive strength of the plate is developed for predicting the ultimate postbuckling shear strength of a plate. For common design parameters of most bridge and building structures, this compression approach produces strengths that are closer to experimental and finite element results than the best and commonly accepted formulation based on tension field action. Overall, the results of this study show that a compression approach to predicting the postbuckling shear capacity of plates is an honest representation of shear buckling mechanics and has good correlation to extensive experimental results, where in many cases improved correlation is seen compared to formulations based on tension field action.

Keywords: tension field, shear buckling, postbuckling, plate girder, plate buckling 


\section{Introduction}

Plate shear buckling is an intriguing phenomenon because, unlike compressive structural elements (a column, for example) that lose their load-carrying capacity once elastic buckling has occurred, plates that elastically buckle due to shear still possess a significant amount of postbuckling shear strength. This postbuckling behavior has attracted the attention of researchers and engineers since the 1880s. Attempts to quantify this behavior led to the historical development of tension field theory, which argues that the source of this postbuckling shear strength is the development of tensile stresses in a defined diagonal field that is mobilized postelastic shear buckling. Beginning with Wagner in 1931 [5], more than a dozen proposals have been developed to explain and predict the postbuckling shear strength based on tension field action. Previous authors have provided extensive discussions on the various proposed plate shear buckling models throughout the literature [1, 2, 3], and all are based on tension field action. As Yoo and Lee [3] point out, this fact “... is testimony to the complexity of tension field action. This may be the largest number of failure theories devoted to a single topic in structural mechanics." While a tension field does form, compression is always the catalyst to buckling, and further, many of the assumptions inherent to tension field theory have since been proven to be inaccurate as will be discussed later. These observations motivated the authors to examine postbuckling shear behavior based on a compression approach.

Tension field theory is based on the key assumptions that (1) compressive stresses cease to increase in the postbuckling range [3,4], and (2) the stiffeners, flanges, or both anchor the tension field. The first assumption was proposed by H. Wagner in 1931 and stated that once elastic shear buckling occurred in the web, compressive stresses do not increase and any additional (or postbuckling) shear strength is mobilized due to the formation of diagonal tensile 
stresses $[1,5,6,7]$. This assumption is simultaneously the most important and most controversial because accepting it transforms a buckling problem, which is inherently a compression problem, into one based on tension. It is a fascinating historical irony to formulate a buckling problem in terms of tension, but one rooted in compelling experimental observations. However, the assumption that compressive stresses do not increase in the postbuckling range was shown not to be accurate based on findings from numerous authors using finite element (FE) analysis [2, 3, 8, 9, 10, 11]. In fact, near the edges, compressive stresses increase considerably [3].

The second assumption has its basis in the earliest recorded explanation for the postbuckling shear strength of stiffened plate girder webs offered by J. M. Wilson in $1886[1,12]$. His explanation arguably established the foundation of tension field theory by suggesting that the transverse stiffeners act like the posts of a Pratt truss, with the web handling the duty of carrying the diagonal tensile stresses. However, previous researchers have found that the large axial loads expected to develop in the transverse stiffeners due to anchoring the diagonal tension field were smaller than expected for a truss action to develop as assumed $[3,8,9,13]$. Similarly, Yoo and Lee [3] found that the vertical stresses reduce to zero near the flange, thus indicating that the flange does not act as an anchor to the tension field.

This paper draws parallels to axially compressed simply supported plates as shown in Figure 1. Comparing Figures 1(a) and (b) we note that, in an elastic state, a plate in pure shear is similar to an axially compressed plate except that it is loaded on a diagonal with equal tensile stresses acting perpendicularly. In Figures 1(c) and (d) we note that in the postbuckling range, both the axially compressed plate and the pure shear loaded plate develop a field of tension perpendicular to the field of compression. It is this tension field, in both cases, that allows postbuckling strength to develop. In both cases, the compressive stresses increase at the edges leading to 
similar patterns of stress distributions. Physically this distribution can be explained by considering that the out-of-plane deformations are largest at the center of the plate. The larger the out-of-plane deformations the smaller the axial rigidity, therefore near the center, the stresses will not increase much (or at all) after elastic buckling. Near the edges, the out-of-plane deformations are much smaller and therefore the stresses continue to increase after elastic buckling.

This paper presents a novel approach to predicting the postbuckling shear capacity of plates based on the compressive behavior dominating the mechanical response. The proposed approach does not ignore the tension field, which is actually shown to provide additional stability such that postbuckling shear capacity may be mobilized. Closed-form equations are presented to predict the postbuckling (ultimate) shear buckling capacity of steel plates. Note that it is not the authors' intention to propose that these equations be directly incorporated into design codes. To meet such a goal, the equations may need to be simplified and perhaps also developed for a broader range of parameters. The fundamental goal of the work presented in this paper is to show the strong promise of a compression-based model for predicting the ultimate buckling load of a plate loaded in shear.

Since, as just illustrated, the behavior of a plate under pure shear is similar to that under pure axial load, the proposed approach is based on considering the plate acting as a column on a diagonal. The parallel of this approach to axially loaded plates is illustrated by comparing Figures 1(e) and (f). In an axially loaded plate, the "equivalence condition" for evaluating the postbuckling strength of the plate is done by transforming the postbuckling stress distribution shown in Figure 1(c) into a stress distribution acting over an equivalent width, $b_{e}$ [14]. For plates loaded in pure shear, we propose instead to make the equivalence condition based on the length 
of the diagonal column. The equivalent column length, $L_{e}$, is equal to the diagonal length of the plate minus the width of the tension field. The challenge is then to predict (1) the width of the tension field, (2) the axial load on this equivalent column, and (3) convert that axial load to a shear load. This paper illustrates this procedure to arrive at a formulation to predict the postbuckling shear capacity of plates. This compression approach is compared to the best and most well-known formulation for postbuckling shear strength of plates developed by Basler in 1961 [4], which is based on tension field theory. The next section therefore describes Basler's approach in detail.

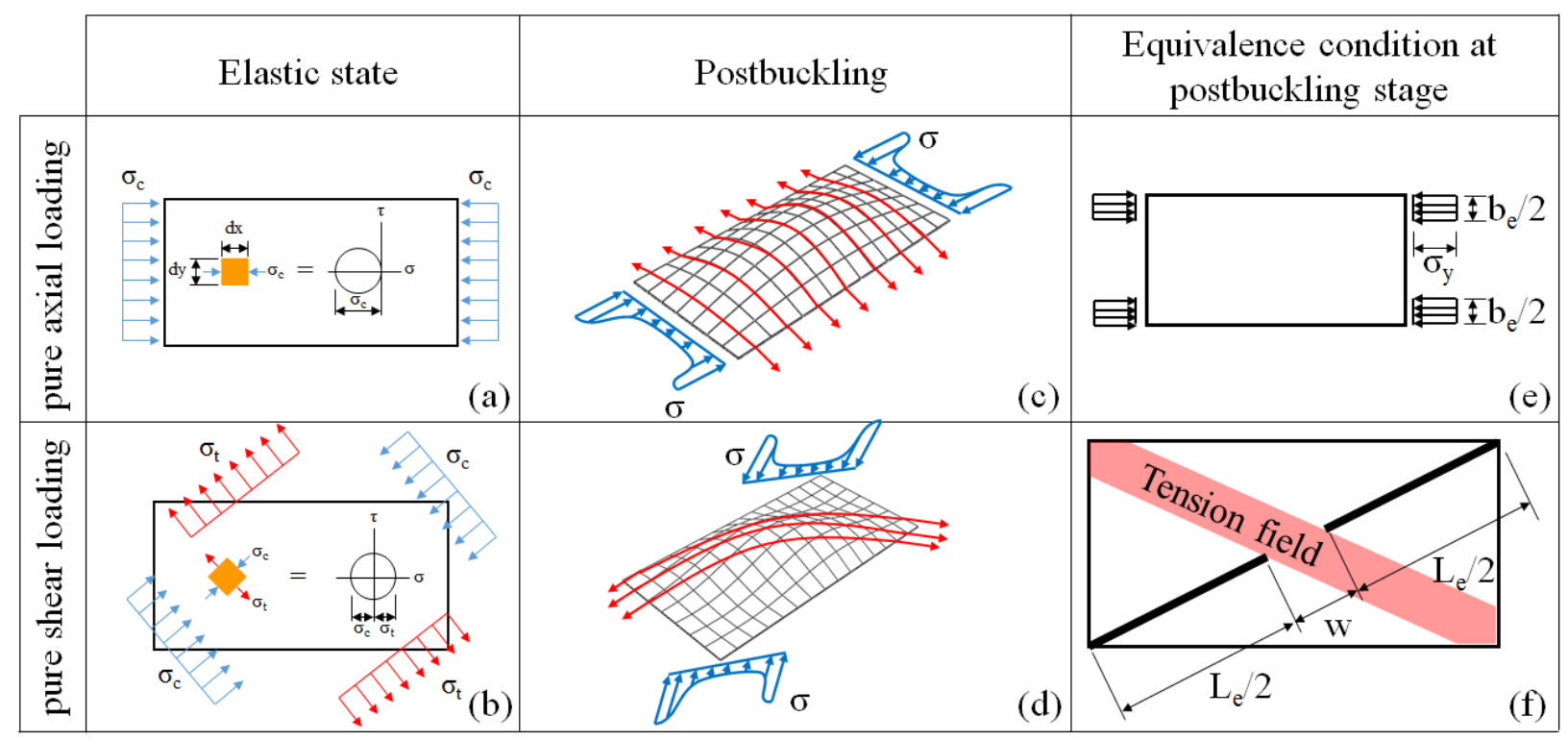

Figure 1. Plate behavior (simply supported) under pure axial load compared to pure shear load.

\section{Basler's Tension Field Approach}

White and Barker [2] compare the shear resistance of the twelve "most promising" tension field based models to the experimental results of 115 to 129 tests of steel I-girders. They found the model by Basler [4], which is implemented in AASHTO [15] and AISC [14], to have the "best combination of accuracy and simplicity". This section therefore focuses on this Basler model, which will be used as a comparison to a compression model that will be developed in this paper. 
In addition, Porter et al. [16], and Höglund [17, 18] will be briefly discussed in this section since these currently serve as the basis for the European design codes $[1,15,16,17]$.

In 1961, Konrad Basler suggested a model to calculate the ultimate postbuckling shear strength of steel plate girders derived from the development of diagonal tension field stresses and based on the assumptions previously discussed [1, 4]. Figure 2 shows a schematic for the tension field of a simply supported plate at the ultimate postbuckling shear stress, $\tau_{u}$.
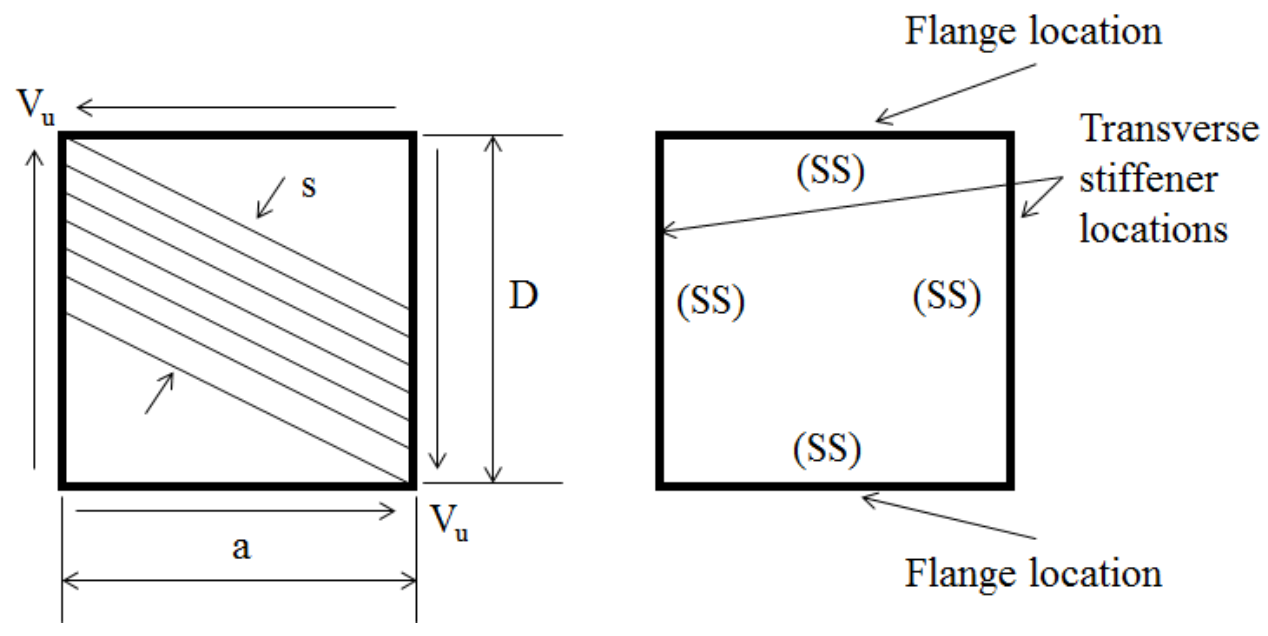

Figure 2. Orientation of the diagonal tension field at $\tau_{u}$ for a plate with simple supports (SS) assumed for all four edges. $D$ is the depth of the plate, and $a$ is the span between transverse stiffeners.

The flanges were assumed to be too flexible to resist any vertical loading from the diagonal tension field, thus this field was oriented such that the vertical component of the tensile stresses was resisted by the transverse stiffeners $[1,4]$. This hypothesis corresponded with the Pratt truss observation made by Wilson in $1886[1,12]$.

Based on the model shown in Figure 2, Eqn. (1) was developed to calculate the $\tau_{u}$ value of a simply supported steel plate. Eqn. (1) is a modification by Gaylord, Fujii, and Selberg [1, 19, 20, 21] of the equation originally-proposed by Basler. 


$$
\tau_{u}=\tau_{c r}+\sigma_{y}\left(1-\frac{\tau_{c r}}{\tau_{y}}\right)\left(\frac{\sin \theta_{d}}{2+\cos \theta_{d}}\right)
$$

The ultimate postbuckling shear load, $V_{u}$, can be calculated by multiplying $\tau_{u}$ by $D t_{w}$, where $t_{w}$ is the thickness of the plate and $D$ is the depth of the plate as shown in Figure 2. In Eqn. (1), $\sigma_{y}$ and $\tau_{y}$ are the yield and shear yield strengths of the plate, respectively, $\theta_{d}$ is the angle of the panel diagonal, and $\tau_{c r}$ is the elastic shear buckling stress. $\tau_{y}$ may be calculated as $0.6 \sigma_{y}$ [14], while $\tau_{c r}$ may be calculated from $[1,22]$ :

$$
\tau_{c r}=\frac{k \pi^{2} E}{12\left(1-v^{2}\right)\left(D / t_{w}\right)^{2}}
$$

where $E$ is Young's modulus, $v$ is Poisson's ratio, $D / t_{w}$ is the slenderness ratio, and $k$ is the shear buckling coefficient. The $k$ value depends on the span-to-depth ratio, $a / D$ (see Figure 2), as well as the assumed boundary conditions. For the four-sided simply supported plate shown in Figure $2, k=k_{s s}$ may be calculated as $[1,22]$ :

$$
\begin{aligned}
& k_{s s}=4.00+\frac{5.34}{(a / D)^{2}} \text { for } a / D<1 \\
& k_{s s}=5.34+\frac{4.00}{(a / D)^{2}} \text { for } a / D \geq 1
\end{aligned}
$$

A simplification of Eqn. (3) is used in AASHTO [15] and AISC [14] as proposed originally by Vincent [2] by using the integer 5.00 in lieu of both 5.34 and 4.00, thus resulting in one equation for all $a / D$ ratios. A maximum difference of $5 \%$ is noted in this case [2].

For situations in which the flange is explicitly considered, equations to calculate $k$ were developed that interpolate the value between two extreme cases - a flange modeled as providing 
either a simple or a fixed support to the web (the stiffeners are typically treated as simple supports [1]). These equations for $k$ can be found in [6,7].

From Eqn. (1), $\tau_{u}$ is a summation of $\tau_{c r}$ plus the second term that represents the stress that develops in a defined tension field. This underscores the use of Wagner's assumption in Basler's model: once $\tau_{c r}$ has been reached, the only source of postbuckling strength up to $\tau_{u}$ is derived from the diagonal tension field stresses.

Basler's model is related to the Cardiff tension field theory model proposed by Porter et al. [16], except that the latter model explicitly accounts for the presence of the flanges in anchoring the tension field and does not impose a restriction on the orientation of the diagonal tension field. This means that the tension field could be anchored by both the transverse stiffeners and the flanges [1]. An interesting characteristic of the Cardiff model is that several other proposed tension field theories, including the Basler model, are actually specialized cases of this model [1, 16]. By assuming that the flanges cannot develop moment resistance, the Cardiff model reduces to Basler's model.

T. Höglund's theory does consider compression through the principal stresses, but it is still largely based on tension field action $[17,18]$ and it is not similar to that developed by the authors. Their model assumes that the ultimate postbuckling shear strength of a girder is the sum of (1) $V_{w}$, the web shear resistance and (2) $V_{f}$, the shear resistance offered by the flanges. Höglund assumes that $V_{w}$ develops due to what he called a rotated stress field (i.e., the decreasing angle of the principal stresses as the shear load increases beyond elastic buckling) and it considers both the tension and compression principal stresses. $V_{f}$ is assumed to develop due to a diagonal tension stress field, which is very similar to the diagonal tension field observed in the 
Cardiff model except that in Höglund's model it is oriented between the top and bottom flanges only.

\section{Finite Element Models}

In the sections that follow, the postbuckling mechanics of steel plates loaded in pure shear will be examined through finite element analysis. Therefore, this section describes the development of the finite element models and validates these models by comparison to experimental results.

\subsection{Boundary conditions and mesh}

Figure 3(a) shows the assumed boundary conditions, while Figure 3(b) shows the stresses in the plate before the elastic shear buckling stress, $\tau_{c r}$, is reached. A state of pure shear was observed in the model since the angle of the principal stress, $\varphi$, was $45^{\circ}$ and the principal stresses in

tension and compression ( $\sigma_{\operatorname{Max}}$ and $\sigma_{\operatorname{Min}}$, respectively) were equal to one another and also equal to $\tau=V /\left(D \cdot t_{w}\right)$, where $V$ is the applied load.

The FE mesh and first mode buckled shapes are shown in Figure 4 for FE models with $D=$ $1.47 \mathrm{~m}, a=1.47,2.06,2.21,2.94,3.68$, and $4.41 \mathrm{~m}$, and $t_{w}=0.011 \mathrm{~m}$. The FE models were all meshed using S4 (doubly curved, general-purpose, finite membrane strains) shell elements [23]. Mesh convergence studies were conducted using an eigenvalue extraction analysis. Various mesh densities were studied, and the selected meshes typically had percent errors less than $2.5 \%$. Percent errors were calculated by taking the difference of $\tau_{c r}$ based on FE from that based on Eqn. (2) and dividing by $\tau_{c r}$ based on Eqn. (2). 


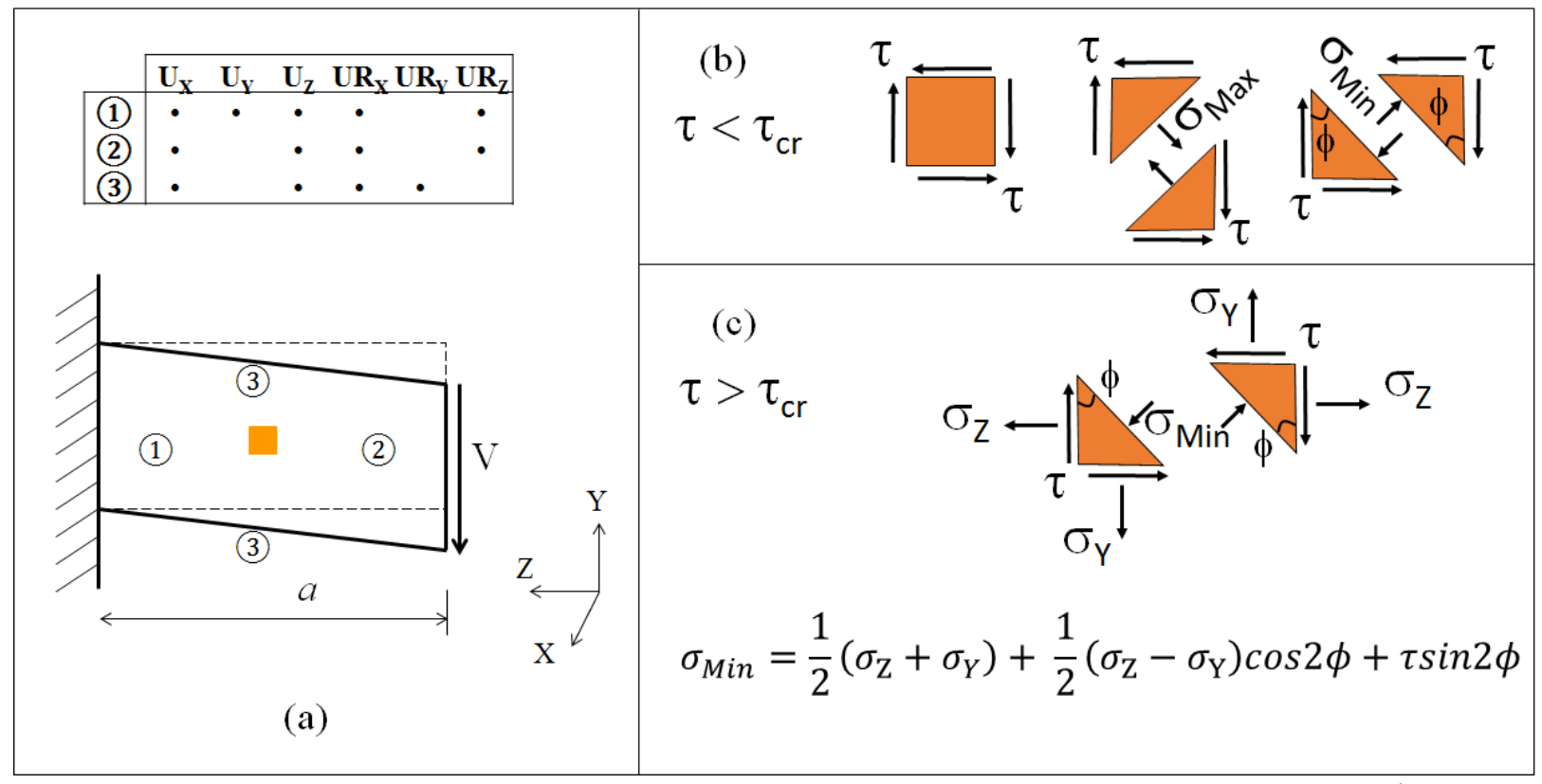

Figure 3. (a) Boundary conditions imposed in the finite element model to simulate pure shear loading, where a "•" indicates a restrained translational (U) or rotational (UR) degree of freedom; and stress state in an infinitesimally small element (b) before elastic buckling and (c) after elastic buckling.
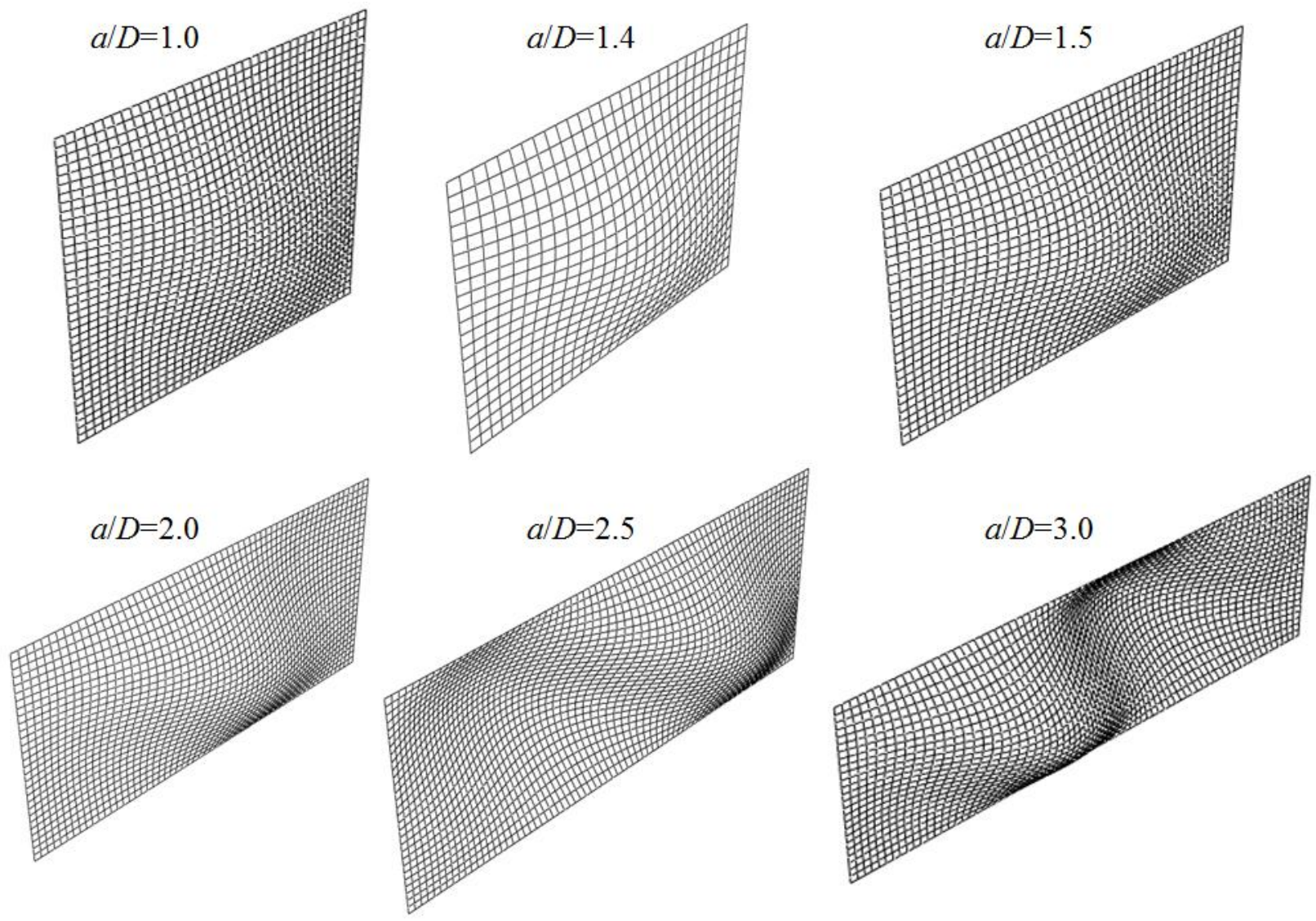

Figure 4. Mesh densities for FE models 1 through 6. 


\subsection{FE model validation}

Previous work by the authors validated the nonlinear postbuckling analysis procedures used for these FE models at both ambient and elevated temperatures [10]. In this paper, additional FE model validation studies were done by comparing the $\mathrm{FE}$ results to 16 experiments as presented in Table 1. In this table, the FE/Exp value equals the FE $V_{u}$ value $\left(V_{u}^{F E}\right)$ divided by the experimental $V_{u}$ value $\left(V_{u}{ }^{E x p}\right)$. The dimensions and $V_{u}{ }^{E x p}$ values were taken from [17]. $V_{u}{ }^{F E}$ was determined by examining the load-displacement curve and selecting the point where the loaddisplacement curve becomes horizontal or reverses slope as discussed in detail in [10].

Table 1 represents the published results of numerous experiments conducted over several decades. Each researcher adopted a different nomenclature for their test specimens. To maintain consistency with the historical record, the names of each test specimen as originally published are preserved in Table 1.

Table 1. Comparison of FE and experimental $V_{u}$ values.

\begin{tabular}{|c|c|c|c|c|c|c|c|c|c|c|}
\hline Specimen & $\begin{array}{c}\mathrm{a} \\
(\mathrm{mm})\end{array}$ & $\begin{array}{c}\mathrm{D} \\
(\mathrm{mm})\end{array}$ & $\begin{array}{c}\mathrm{t}_{\mathrm{w}} \\
(\mathrm{mm})\end{array}$ & $\mathrm{a} / \mathrm{D}$ & $\mathrm{D} / \mathrm{t}_{\mathrm{w}}$ & $\mathrm{t}_{\mathrm{f}} / \mathrm{t}_{\mathrm{w}}$ & $\begin{array}{c}\sigma_{\mathrm{y}} \\
(\mathrm{MPa})\end{array}$ & $\begin{array}{l}\mathrm{V}_{\mathrm{u}}^{\mathrm{FE}} \\
(\mathrm{kN})\end{array}$ & $\begin{array}{l}\mathrm{V}_{\mathrm{u}}^{\operatorname{Exp}} \\
(\mathrm{kN})\end{array}$ & $\mathrm{FE} / \mathrm{Exp}$ \\
\hline G6-T1 $1^{[24]}$ & 1905 & 1270 & 4.9 & 1.50 & 259 & 4.04 & 253 & 542 & 516 & 1.05 \\
\hline G7-T1 $1^{[24]}$ & 1270 & 1270 & 4.98 & 1.00 & 255 & 3.92 & 253 & 649 & 623 & 1.04 \\
\hline G7-T2 $2^{[24]}$ & 1270 & 1270 & 4.98 & 1.00 & 255 & 3.92 & 253 & 649 & 645 & 1.01 \\
\hline G8-T1 $1^{[24]}$ & 3810 & 1270 & 5.08 & 3.00 & 250 & 3.76 & 263 & 403 & 378 & 1.07 \\
\hline $\mathrm{G} 8-\mathrm{T} 2^{[24]}$ & 1905 & 1270 & 5.08 & 1.50 & 250 & 3.76 & 263 & 562 & 445 & 1.26 \\
\hline $\mathrm{G} 8-\mathrm{T} 3^{[24]}$ & 1905 & 1270 & 5.08 & 1.50 & 250 & 3.76 & 263 & 562 & 516 & 1.09 \\
\hline $2.2^{[25]}$ & 1440 & 600 & 2 & 2.40 & 300 & 3.00 & 255 & 75 & 75 & 1.00 \\
\hline $\mathrm{US} 3 / 5^{[26]}$ & 788 & 359 & 2.7 & 2.19 & 133 & 4.44 & 257 & 99 & 90 & 1.10 \\
\hline STG1 $^{[27]}$ & 551 & 279 & 2 & 1.97 & 140 & 3.95 & 255 & 53 & 60 & 0.89 \\
\hline $\mathrm{STG}_{4}^{[27]}$ & 498 & 251 & 1.25 & 1.98 & 201 & 5.12 & 246 & 25 & 35 & 0.71 \\
\hline $\mathrm{RTG1}^{[27]}$ & 305 & 305 & 1.27 & 1.00 & 240 & 3.54 & 244 & 40 & 40 & 1.01 \\
\hline $\mathrm{RTG}^{[27]}$ & 305 & 305 & 1.27 & 1.00 & 240 & 3.70 & 244 & 40 & 41 & 0.99 \\
\hline $\mathrm{MSO}^{[28]}$ & 947 & 608 & 2.01 & 1.56 & 302 & 5.02 & 261 & 100 & 94 & 1.06 \\
\hline $\mathrm{CP} 1 / 1^{[29]}$ & 747 & 500 & 2.04 & 1.49 & 245 & 3.92 & 246 & 88 & 88 & 1.00 \\
\hline$S-2^{[30]}$ & 581 & 319 & 3.2 & 1.82 & 100 & 3.28 & 352 & 158 & 161 & 0.98 \\
\hline$S-3^{[30]}$ & 577 & 477 & 3.2 & 1.21 & 149 & 3.28 & 317 & 208 & 198 & 1.05 \\
\hline
\end{tabular}

Note: Superscripts [24], [25], [26], [27], [28], [29], [30] are references to publications. 
All of the FE models in Table 1 used the boundary conditions from Figure 3. Results in Table 1 give confidence that the FE models can capture the ultimate postbuckling shear strength of plates. It is seen that the FE models predicted $V_{u}$ values to within about $10 \%$ of the published experimental values with only two notable exceptions. For specimen G8-T2, the FE/Exp value was 1.26, however specimen G8-T3, which was a repeat of experiment G8-T2 had a FE/Exp value of 1.09. For specimen STG4, the flange-to-web thickness ratio $\left(t_{f} / t_{w}\right)$ was quite large compared to other tests. It is hypothesized that the flanges, while neglected in the FE model, would have contributed to the ultimate postbuckling shear strength in the experiment and, thus, the correlation of FE to experimental results was not as accurate as the other data.

\section{Plate Stresses at the Ultimate Postbuckling State}

Yoo and Lee [3] present a study of the mechanics of plate buckling using finite element results. Their study, however, is only for one square plate $(a / D=1.0)$. To expand the discussion of shear buckling mechanics, plates with $a / D$ values of 1.0, 2.0, and 3.0 are discussed here. Both the normal and principal stresses in the plate are considered in this study. The normal stresses are referred to as $\sigma_{11}$ and $\sigma_{22}$, which relate to S11 and S22 outputs in the Abaqus finite element results. $\sigma_{11}$ and $\sigma_{22}$ represent the horizontal and vertical directional stresses, respectively. The principal stresses relate to SMAX and SMIN outputs in Abaqus, referred to as $\sigma_{M a x}$ and $\sigma_{\text {Min }}$ in this paper. Since tension is positive, $\sigma_{\text {Max }}$ is related to the maximum tensile stress and $\sigma_{\text {Min }}$ the maximum compression stress. All of the finite element stresses shown in this paper represent the average stress through the plate thickness (the average of SP:1 and SP:5 in Abaqus notation). 


\subsection{Normal stresses}

At and before the shear load reaches the elastic shear buckling load, $V_{c r}, \sigma_{11}$ and $\sigma_{22}$ equal zero, which is consistent with a plate loaded in pure shear. After buckling these stresses increase and a new state of equilibrium exists in the plate. Figures 5(b) through (d) plot $\sigma_{11}$ and $\sigma_{22}$, normalized by the yield stress $\sigma_{y}$, at the ultimate postbuckling load $\left(V_{u}\right)$ for a horizontal strip at the center of the plate (Figure 5(a)). Results for $a / D$ equal to $1.0,2.0$, and 3.0 and $D / t_{w}$ values of 134 are plotted. Figures 5(f) through (h) plot a similar result, but for a vertical strip at the center of the plate (Figure 5(e)). Note that for all $a / D$ values the stresses at the location of the flanges are essentially zero. While this result is influenced by the boundary conditions of the finite element model, these boundary conditions reflect a pure shear loading state and thin flanges, where 'thin' will be defined later and shown, by validation with experimental results, to be within a common range for design.

Figure 6 is similar to Figure 5 except that the normal stresses are plotted along the tension diagonal and compression diagonal. Again it is seen that at the postbuckling stage, the stresses increase significantly. Similar to Figure 5, the horizontal stresses, $\sigma_{11}$, are larger than the vertical stresses $\sigma_{22}$. In both normal stress plots, $\sigma_{11}$ and $\sigma_{22}$ increase with increasing $a / D$ values.
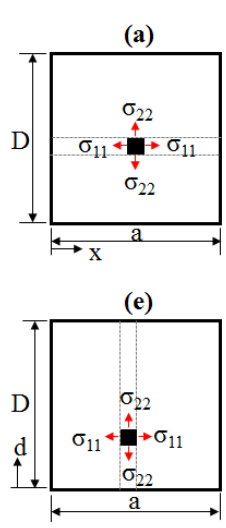

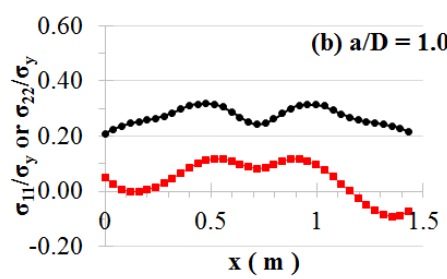

0.60
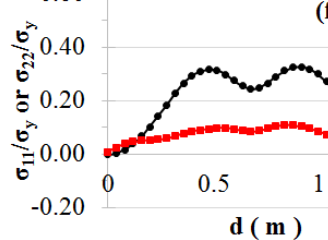

(f) $\mathbf{a} / \mathbf{D}=1.0$

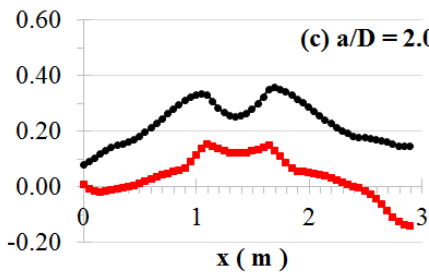

)

(g) $\mathbf{a} / \mathbf{D}=\mathbf{2 . 0}$

$0.40 \quad(\mathrm{~g}) \mathrm{a} / \mathrm{D}=2.00 .40$

0.20

0.00
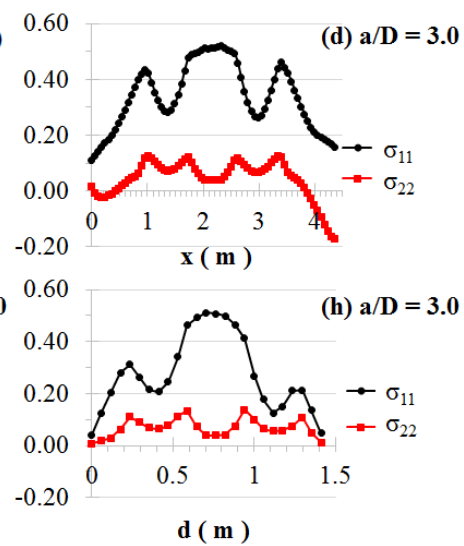

Figure 5. Normal stresses in horizontal and vertical strips at $V_{u}$. 


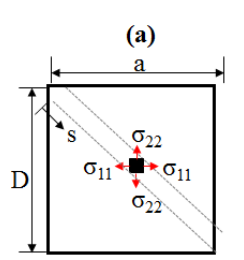

(e)

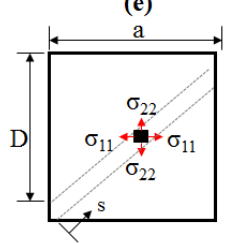

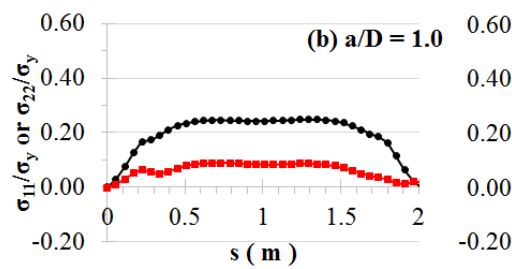
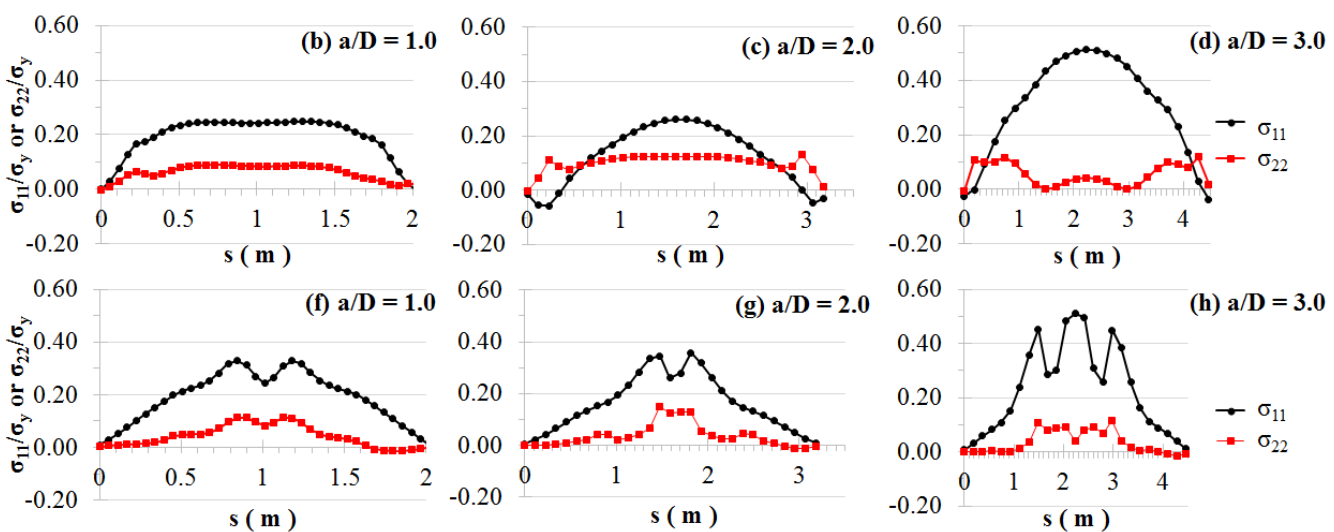

Figure 6. Normal stresses in diagonal strips at $V_{u}$.
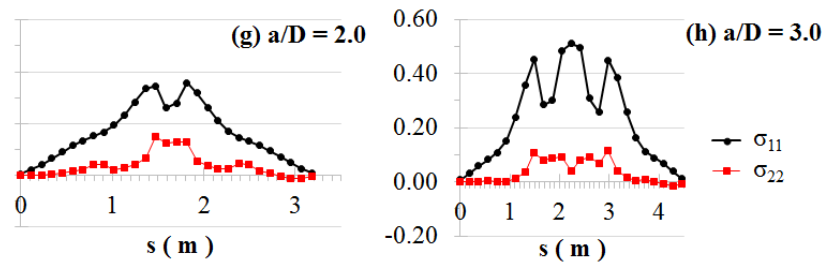

\subsection{Principal stresses}

The normal stresses discussion was important for understanding the change in stress state that develops in a plate after buckling (i.e., it transitions from the stress state shown in Figure 3(b) to that shown in Figure 3(c)). In addition to normal stresses in both the tension and compression fields, it is important to examine the principal stresses since these represent the maximum stresses on a plate. Figures 7(a) and (b) plot $\sigma_{\operatorname{Max}}$ from corner to corner of a plate with $a / D$ equal to 2.0 and $D / t_{w}$ equal to 147 . This strip represents the tension field area. Figures 7(a) and (c) plot $\sigma_{\text {Min }}$ along the same diagonal. It is seen in Figure 7(b) that the maximum tensile stresses (i.e., $\sigma_{M a x}$ ) at $V_{u}$ equals on average about $40 \%$ of $\sigma_{y}$ and the maximum compression stresses (i.e., $\sigma_{\text {Min }}$ ) at $V_{u}$ equals on average about half of $\sigma_{\operatorname{Max}}($ Figure 7(c)). If one considers the von Mises yield function separately on the upper and lower surfaces of the plate thickness, the plate reaches yield along this diagonal (recall that the stresses shown are averages through the plate thickness). $\sigma_{\text {Max }}$ remains essentially constant, but at $V_{u} \sigma_{\text {Min }}$ decreases below that at $V_{c r}$ near the center of the plate, and more than doubles the $V_{c r}$ value at the edges. Also, note that the shape of the stress distribution is similar to that of an axially loaded plate as illustrated in Figure 1(c).

Figure 8(a) is similar to Figure 7(a) except that it plots $\sigma_{\operatorname{Min}}$ along the compression diagonal. The intent is to begin to observe the plate acting as a column. Superimposed on Figure $8(\mathrm{~b})$ is the 
width of the tension field, $w$. This width is drawn to scale based on the compression model that will be described later. Note that within this width, $\sigma_{\min }$ reduces significantly as the plate is loaded from $V_{c r}$ to $V_{u}$. Also, at the edges, $\sigma_{m i n}$ increases as the plate is loaded from $V_{c r}$ to $V_{u}$.

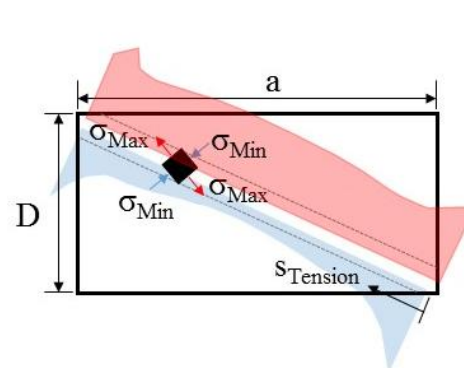

(a)

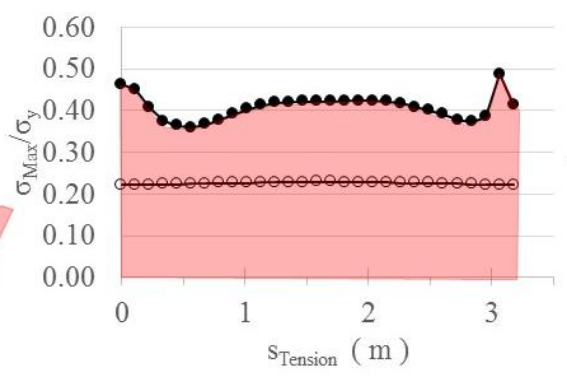

(b)

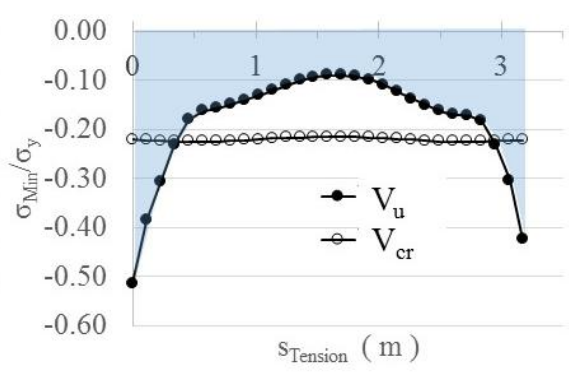

(c)

Figure 7. Principal stresses (maximum, $\sigma_{\max }$, and minimum, $\sigma_{\min }$ ) plotted along the tension field (corner to corner) for $a / D=2.0, D / t_{w}=147$, and $\sigma_{y}=250 \mathrm{MPa}$.
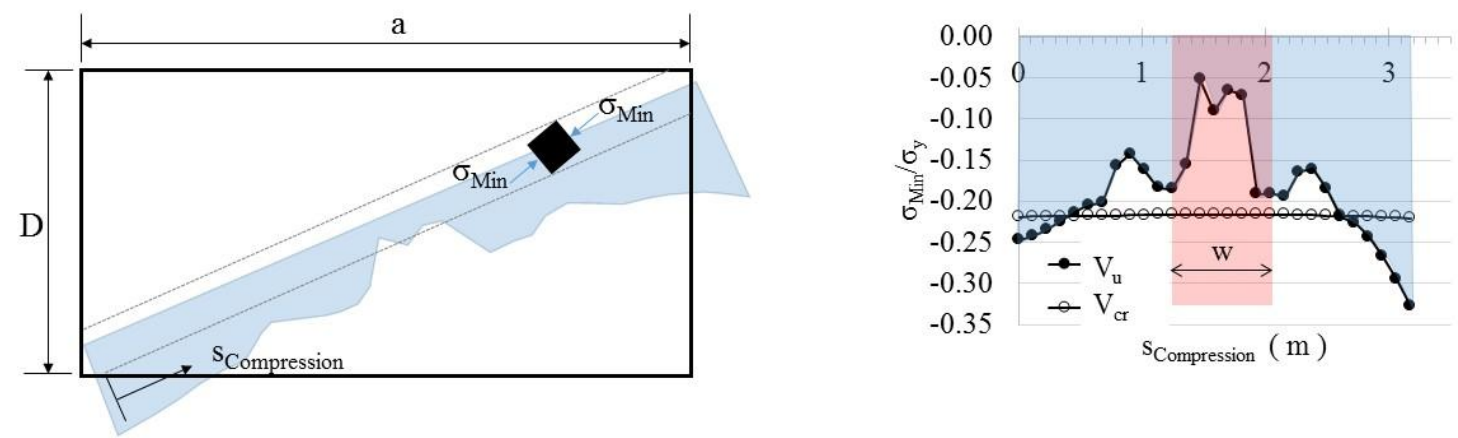

Figure 8. Minimum (compression) principal stresses plotted along the compression diagonal (corner to corner) for $a / D=2.0, D / t_{w}=147$, and $\sigma_{y}=250 \mathrm{MPa}$.

Figure 7 shows that the stress distribution on the compression field at $V_{u}$ has a similar pattern to that of an axially compressed plate (Figure 1(c)). Figure 9 examines this stress pattern (and magnitude) of $\sigma_{\text {Min }}$ across various cuts of the plate. In all cases it is seen that the stresses increase towards the edges and have a similar in pattern to that expected in an axially compressed simply supported plate. 

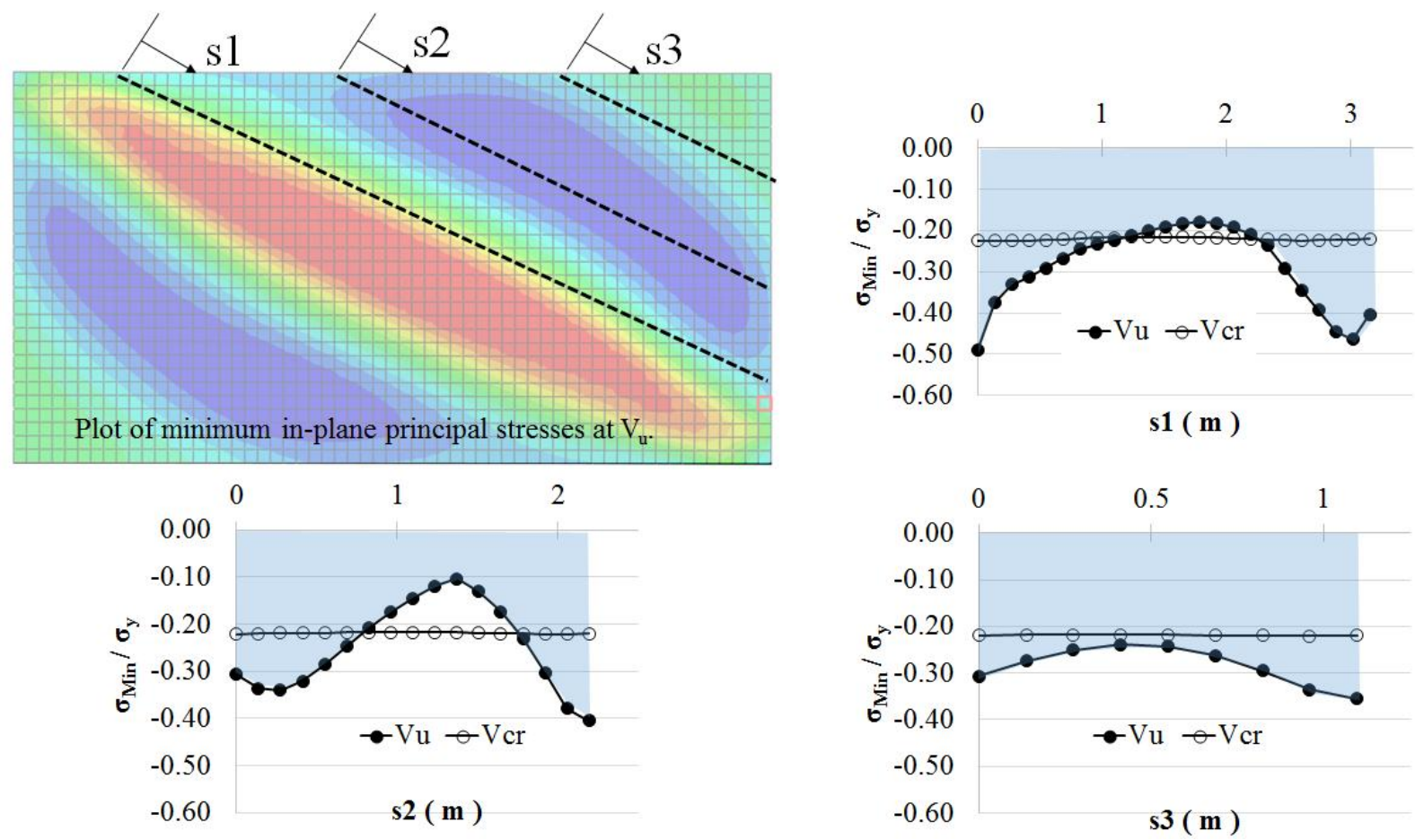

Figure 9. Maximum compression stresses $\left(\sigma_{\text {Min }}\right)$ across various cuts of the compression field for $a / D=2.0$ and $D / t_{w}=147$.

Figure 10 shows the value of the angle of principal stresses, $\theta_{p}$, at various locations for plates with $a / D$ of 1.0, 2.0, and 3.0 at $V_{u}$. These are the same plates previously discussed in Figures 5 and 6. Four points (A, B, C, and D) were selected at various locations with respect to the tension field and diagonal compression line as drawn in Figure 10(d). The $\theta_{p}$ values are tabulated in Figure 10(e) and show that at $V_{u}$ these $\theta_{p}$ values are less than $45^{\circ}$, which is the $\theta_{p}$ value at $V_{c r} . \theta_{p}$ values fall within a range of $35^{\circ}$ to $40^{\circ}$ and do not appear to be significantly affected by $a / D$ values or location. 
(a)
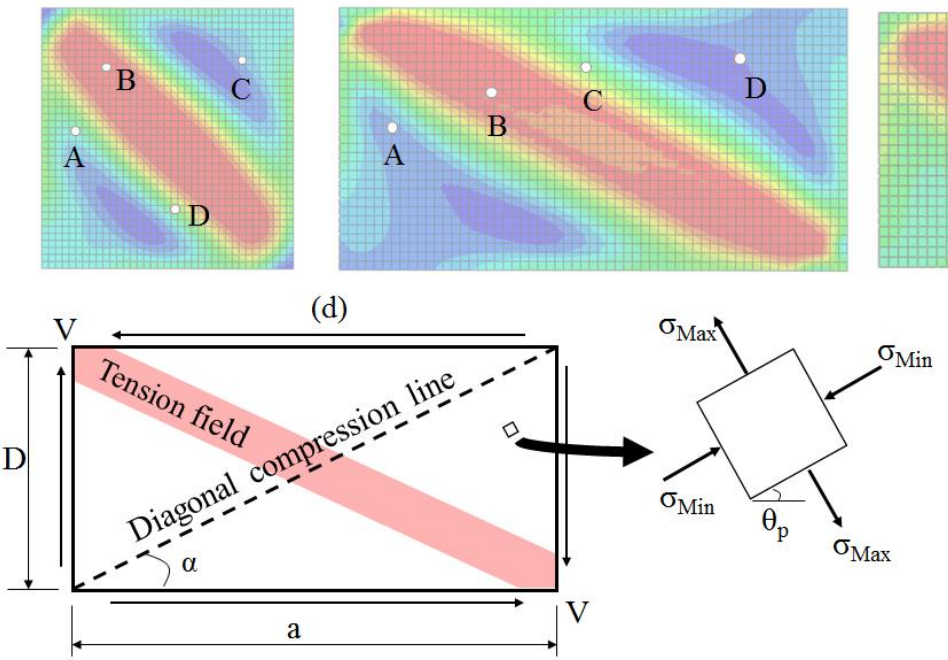

(b)

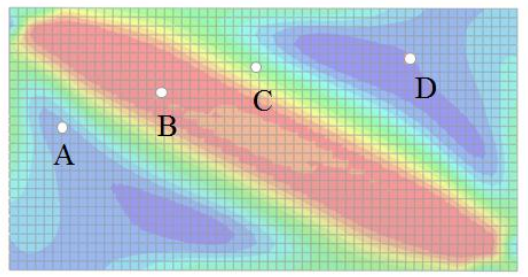

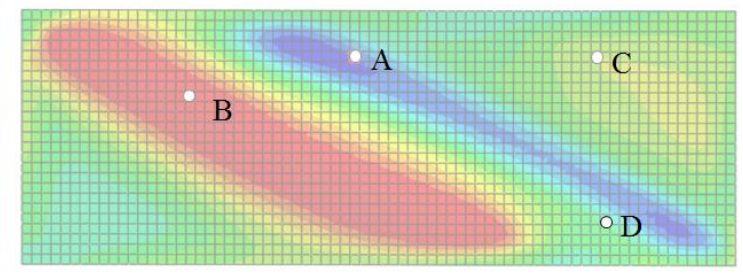

(e)

\begin{tabular}{c|c|c|}
\hline $\mathbf{a} / \mathbf{D}$ & $\boldsymbol{\alpha}$ & $\boldsymbol{\theta}_{\mathrm{p}}{ }^{\mathbf{a}}$ \\
\hline 1.0 & $45^{\circ}$ & $37^{\circ}, 38^{\circ}, 39^{\circ}, 40^{\circ}$ \\
\hline 2.0 & $26.6^{\circ}$ & $37^{\circ}, 39^{\circ}, 39^{\circ}, 40^{\circ}$ \\
\hline 3.0 & $18.2^{\circ}$ & $38^{\circ}, 35^{\circ}, 40^{\circ}, 39^{\circ}$ \\
\hline
\end{tabular}

Figure 10. Angle of principal stresses at various locations for $a / D$ values of (a) 1.0, (b) 2.0 , and (c) 3.0 at $V_{u}$; (d) diagram of tension field, centerline of equivalent column, and angle $\alpha$; (e) $\alpha$ and $\theta_{p}$ values.

\section{A Compression-Based Approach for Shear Buckling}

Using the mechanics study of the previous section, a compression model is developed for defining and predicting the postbuckling capacity of a plate under shear. Since buckling is inherently a phenomenon based on compression, it is assumed that the compression field dominates the physical response instead of tension, but the tension field is not ignored. Figure 11 illustrates the concept of plate shear buckling using a compression approach. In the elastic state, the plate loaded in pure shear is assumed to have a concentrated band of compression as shaded and circled in Figure 11(a). It is assumed that the compression stresses are all concentrated in this region, which is converted to an equivalent column with an equivalent moment of inertia, $I_{e q}$, as shown in Figure 11(b). When the plate is loaded to the elastic shear buckling load, $V_{c r}$, the load on the equivalent column equals $P_{c r}$ and the equivalent column buckles as shown in Figure 11(c).

At the ultimate shear load state, $V_{u}$, the plate has developed an additional postbuckling capacity as defined earlier. A clearly visible tension field has formed, with width $w$, as shown in 
Figure 11(d). Just like in an axially compressed plate, this tension field is responsible for the post-buckling capacity as it pulls down the plate as it tries to deform out-of-plane after elastic buckling (see Figure 1(c) and (d)). It is assumed that in the postbuckling state, the equivalent column has the same equivalent moment of inertia as in the elastic state (Figure 11(e)). The tension field width, $w$, is assumed to be in sufficient tension so that it is flexurally rigid; therefore, when the plate reaches $V_{u}$, the equivalent column length, $L$, is reduced to a length $L_{e}$ as illustrated in Figure 11(f).

panel under pure shear loading

Figure 11. The equivalent column model for the development of a compression approach to plate shear buckling.

$P_{c r}$ in Figure 11(c) equals the elastic flexural buckling strength of a column:

$$
P_{c r}=\frac{\pi^{2} E I_{e q}}{\left(k_{e 1} L\right)^{2}}
$$

In Eqn. (4), the moment of inertia, $I$, has been replaced with an equivalent moment of inertia, $I_{e q}$, to indicate that this value is for an equivalent structural system. The coefficient $k_{e l}$ is the effective length factor of the equivalent column (Figure 11(c)) and assumed to equal 1.0. 
For the equivalent column representing the postbuckling capacity of Figure 11(f), it will be assumed that the elastic flexural buckling equation still applies, but for a reduced length:

$$
P_{u}=\frac{\pi^{2} E I_{e q}}{\left(k_{e 2} \frac{L_{e}}{2}\right)^{2}}
$$

Solving Eqn (4) for $I_{e q}$, and substituting $k_{e 2}=2.0$ for a compression element that is pinned on one end and free to translate, but not rotate, at the other end, results in the following expression:

$$
P_{u}=P_{c r}\left(\frac{L}{L_{e}}\right)^{2}
$$

The challenge now becomes to relate $P_{u}$ and $P_{c r}$, back to $V_{u}$ and $V_{c r}$, respectively. The stress, $\sigma$, acting over area $A$ (Figure 12(a)) varies in that space as shown in Figures 12(b) and 9. The axial force, $P$, at any distance, $r$, from the tension field (see Figure 12(c)) equals $\int_{0}^{s} \sigma t_{w} d s$. With $t_{w}$ constant, the average axial force, $P_{\text {avg }}$, acting over the area, $A$, in the realm where the equivalent column resides thus equals:

$$
P_{a v g}=\frac{t_{w}}{L_{e} / 2} \int_{0}^{r} \int_{0}^{s} \sigma \cdot d s d r
$$

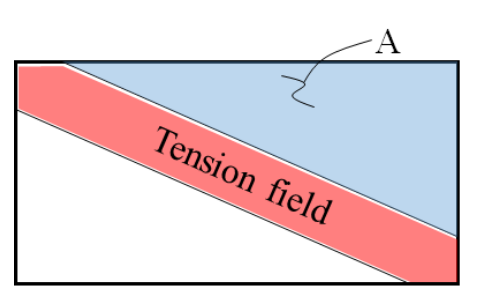

(a)

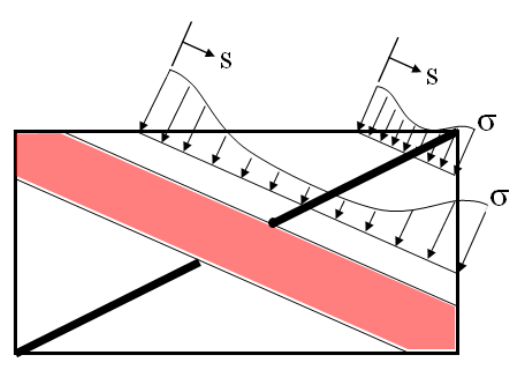

(b)

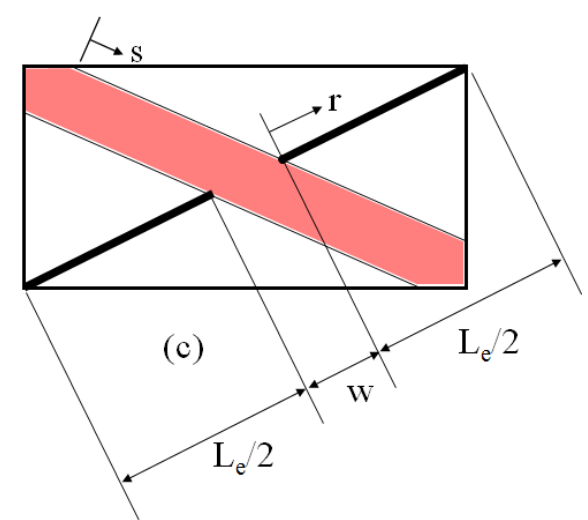

Figure 12. (a) Area, $A$, over which $P_{\text {avg }}$ is calculated, (b) schematic of varying stresses acting over area $A$, and (c) notations used in Eqn. (7). 
At $V=V_{c r}$, it is known that $\sigma=\sigma_{c r}=\tau_{c r}=V_{c r} /\left(D \cdot t_{w}\right)$. Therefore, for $P=P_{c r}$, Eqn. (7)

becomes,

$$
P_{c r}=V_{c r} \cdot \frac{1}{D} \int_{0}^{s} d s
$$

At $V=V_{u}, \sigma$ is equal to the minimum principal stress (i.e. the maximum axial compression stress):

$$
P_{u}=\frac{t_{w}}{L_{e} / 2} \int_{0}^{r} \int_{0}^{s} \sigma_{\operatorname{Min}} \cdot d s d r
$$

It will be assumed that Eqn. (9) collapses to something similar to Eqn. (8), where $P_{u}$ becomes $V_{u}$ times a function, call it $\mathrm{f}(\cdot)$. It is expected that $\mathrm{f}(\cdot)$ will be influenced by geometric parameters such as $a / D, D / t_{w}$, flange thickness, and perhaps other parameters such as material properties.

Substituting Eqn. (8) into Eqn. (6), and setting $P_{u}=V_{u} f(\cdot)$ :

$$
V_{u}=V_{c r}\left(\frac{L}{L_{e}}\right)^{2} \cdot Q_{v}
$$

where

$$
Q_{v}=\frac{\frac{1}{D} \int_{0}^{s} d s}{f(\bullet)}
$$

Due to the complex nature of the stress distributions and magnitudes in the postbuckling stage, it is beyond the scope of this paper to determine precisely what $f(\cdot)$ equals. A simplified assumption will be made by assuming $Q_{v}=1.0$, or in other words $f(\bullet) \approx \frac{1}{D} \int_{0}^{s} d s$. It will be shown by comparison to experimental results that this is a reasonable assumption. Future work will examine $Q_{v}$ in more detail. 
Eqn. (10) requires calculating $L_{e}$, which in turn requires solving for $w$ since $L_{e}=L-w$ from Figure 11(f). In sections to follow, a discussion will be given on how to calculate $w$, which will be based on experimentally validated finite element models.

\section{Formula for Width of Tension Field, w}

\subsection{FE models}

Sixty finite element (FE) models (shown in Table 2) were used to develop an equation to calculate $w$. The first 6 models were each repeated 9 times with different $D / t_{w}$ ratios. All FE models use Young's modulus $=E=2 \mathrm{e} 11 \mathrm{~N} / \mathrm{m}^{2}$ and Poisson's ratio $=v=0.3$. The yield stress was studied at both $\sigma_{y}=250 \mathrm{MPa}$ and $345 \mathrm{MPa}$ as will be discussed later.

Table 2. Matrix of Finite Element (FE) Models.

\begin{tabular}{|c|c|c|c|c|c|c|}
\hline FE Model \# & $\begin{array}{c}\text { Girder length } \\
(\mathrm{m} / \mathrm{ft})\end{array}$ & $\begin{array}{c}\mathrm{D} \\
(\mathrm{m})\end{array}$ & $\begin{array}{c}\mathrm{a} \\
(\mathrm{m})\end{array}$ & $\mathrm{a} / \mathrm{D}$ & $\begin{array}{c}\mathrm{t}_{\mathrm{w}} \\
(\mathrm{mm})\end{array}$ & D/t ${ }^{\mathrm{a}}$ \\
\hline 1 & $27.4 / 90$ & 1.47 & 1.47 & 1.0 & 5 to 13 & 113 to 294 \\
\hline 2 & $27.4 / 90$ & 1.47 & 2.06 & 1.4 & 5 to 13 & 113 to 294 \\
\hline 3 & $27.4 / 90$ & 1.47 & 2.21 & 1.5 & 5 to 13 & 113 to 294 \\
\hline 4 & $27.4 / 90$ & 1.47 & 2.94 & 2.0 & 5 to 13 & 113 to 294 \\
\hline 5 & $27.4 / 90$ & 1.47 & 3.68 & 2.5 & 5 to 13 & 113 to 294 \\
\hline 6 & $27.4 / 90$ & 1.47 & 4.41 & 3.0 & 5 to 13 & 113 to 294 \\
\hline 7 & $33.5 / 110$ & 1.85 & 2.78 & 1.5 & 14 & 132 \\
\hline 8 & $33.5 / 110$ & 1.85 & 5.56 & 3.0 & 14 & 132 \\
\hline 9 & $39.6 / 130$ & 2.24 & 3.35 & 1.5 & 17 & 131 \\
\hline 10 & $39.6 / 130$ & 2.24 & 6.71 & 3.0 & 17 & 131 \\
\hline 11 & $45.7 / 150$ & 2.62 & 3.92 & 1.5 & 20 & 131 \\
\hline 12 & $45.7 / 150$ & 2.62 & 7.85 & 3.0 & 20 & 131 \\
\hline
\end{tabular}

(a) $t_{w}$ values $(\mathrm{mm})=5,6,7,8,9,10,11,12,13$

(b) $D / t_{w}$ values $=113,123,134,147,163,184,210,245,294$

The FE models listed in Table 2 were based on standard plans for typical steel girder highway bridges specified by the Federal Highway Administration (FHWA) for girder lengths of 27.4, 33.5, 39.6, and $45.7 \mathrm{~m}(90,110,130$, and 150 feet, respectively) [31]. Different depths $(D)$ 
were selected to represent different girder lengths and to study the effects of scale. In FE models 1 through 6, web thickness, $t_{w}$, values were selected (ranging from $5 \mathrm{~mm}$ to $13 \mathrm{~mm}$ ) to study a range of slenderness ratios, $D / t_{w}$, equal to 113 through 294 . Six plate span-to-depth ratios $(a / D)$ were selected to cover a wide range of typical design values: 1.0, 1.4, 1.5, 2.0, 2.5, and 3.0.

\subsection{Formulation}

To solve for $V_{u}$ in Eqn. (10) one must solve for $L_{e}$, and in turn to solve for $L_{e}$, one must solve for $w$. Figure 11(f) shows that $L_{e}=L-w$. To develop an empirical formulation for $w, V_{u}$ in Eqn. (10) is set equal to $V_{u}{ }^{F E}, Q_{v}$ is assumed to equal 1.0, and a value of $L_{e}$ is solved for, labeled here as $L_{e}{ }^{*}$ :

$$
L_{e}^{*}=\frac{L}{\sqrt{V_{u}^{F E} / V_{c r}}}
$$

The width that the tension field in Figure 11(f) must be for $V_{u}{ }^{F E}$ to match exactly $V_{u}$ of Eqn. (10), therefore, is $w^{*}=L-L_{e}{ }^{*}$, which is then used to derive an empirical formulation for $w$ as will be discussed next.

FE models 1 through 6 were used to study the effect of $a / D, D / t_{w}$, and $\sigma_{y}$, on $w^{*}$. Figure 13 plots $w^{*}$ versus $a / D$ for $D / t_{w}$ values ranging from 113 to 294 and for $\sigma_{y}$ equal to (a) $250 \mathrm{MPa}$ and (b) $345 \mathrm{MPa}$. These two $\sigma_{y}$ values were selected since they represent common values for steel plate girders. The linear regression of the data points is also presented in Figure 13 and shows that the relationship between $w^{*}$ and $a / D$ is nearly linear for each $D / t_{w}$ value. 

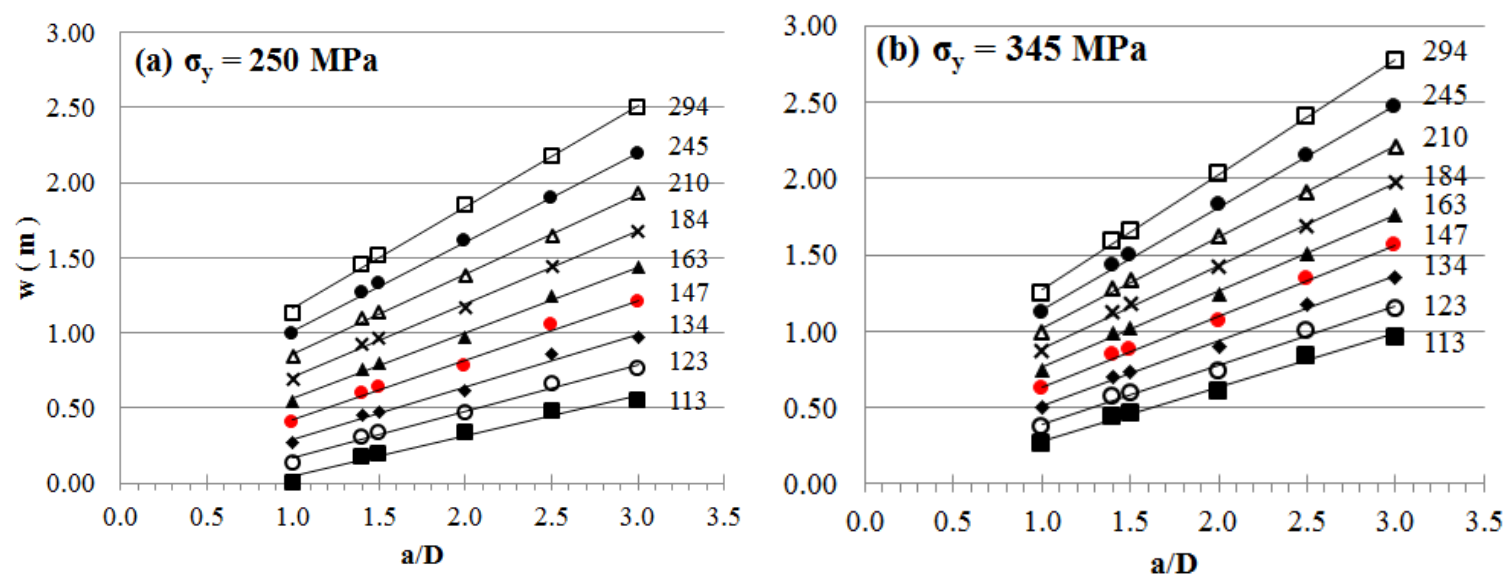

Figure 13. Plot of $w^{*}$ versus $a / D$ for different $D / t_{w}$ values and $\sigma_{y}$ of (a) $250 \mathrm{MPa}$ and (b) $345 \mathrm{MPa}$. The linear regression results are plotted for each set of data points corresponding with (from top to bottom) $D / t_{w}$ values of 294 , 245, 210, 184, 163, 147, 134, 123, and 113.

A comparison of Figures 13(a) and (b) shows that as $\sigma_{y}$ increases, $w^{*}$ (and, therefore, the width of the tension field at $V_{u}$ ) also increases. This implies that a higher $\sigma_{y}$ permits a wider tension field to form. As a/D increases from 1.0 to $3.0, w^{*}$ also increases in part because the angle of inclination of the compression diagonal decreases, therefore it will cross a wider portion of the diagonal tension field. In addition, Figure 13 shows that an increase in $D / t_{w}$ results in a larger $w^{*}$ value.

Since Eqn. (10) does not explicitly account for $\sigma_{y}$, the effect of $\sigma_{y}$ is accounted for through formulations for $w$. Using only the linear regression results of models 1 through 6 , which all have $D=1.47 \mathrm{~m}$, results in the following value of $w$, in units of meters:

$$
\begin{aligned}
& w^{(D=1.47)}=\left(0.4121 \ln \left(\frac{D}{t_{w}}\right)-1.668\right)\left(\frac{a}{D}\right)+0.7768 \ln \left(\frac{D}{t_{w}}\right)-3.8624 \\
& w^{(D=1.47)}=\left(0.4107 \ln \left(\frac{D}{t_{w}}\right)-1.5914\right)\left(\frac{a}{D}\right)+0.6428 \ln \left(\frac{D}{t_{w}}\right)-3.0566
\end{aligned}
$$

Eqns. (13a) and (13b) are for $\sigma_{y}=250 \mathrm{MPa}$ and $345 \mathrm{MPa}$, respectively. Eqn. (13) works well for plates with $D=1.47 \mathrm{~m}$ (FE models 1 through 6) as shown in Table 3, which compares $w^{(D=1.47)}$ 
to $w^{*}$; however, results for FE models $7-12$ show that for deeper sections $w^{(D=1.47)}$ becomes much smaller than $w^{*}$. Eqn. (13) must, therefore, be modified to consider the effects of $D$.

Eqn. (1) calculates $\tau_{u}$ based on two geometric parameters: $a / D$ and $D / t_{w}$. Therefore, two plates with equal $a / D$ and $D / t_{w}$ values, yet different $D$ values, will have the same $\tau_{u}$ value. However, $V_{u}$, and therefore $P_{u}$, are functions of $D$ since $V_{u}=\tau_{u} D t_{w}$, thus $D$ must be explicitly accounted for in the calculation of $w$. FE models 7 through 12 were used for this purpose.

Table 3. Comparing $w^{*}$ to $w^{(D=1.47)}$ [from Eqn. (13)] and $w$ [from Eqns. (14) and (15)].

\begin{tabular}{|c|c|c|c|c|c|c|c|c|c|}
\hline \multirow{2}{*}{ FE Model } & \multirow{2}{*}{$\mathrm{D} / \mathrm{t}_{\mathrm{w}}$} & \multicolumn{3}{|c|}{$\sigma_{\mathrm{y}}=250 \mathrm{MPa}$} & \multicolumn{3}{c|}{$\sigma_{\mathrm{y}}=345 \mathrm{MPa}$} \\
\cline { 3 - 10 } & & $\mathrm{w}^{*}(\mathrm{~m})$ & $\mathrm{w}^{(\mathrm{D}=1.47)} / \mathrm{w}^{*}$ & $1.47 / \mathrm{D}$ & $\mathrm{w} / \mathrm{w}^{*}$ & $\mathrm{w} *(\mathrm{~m})$ & $\mathrm{w}^{(\mathrm{D}=1.47)} / \mathrm{w}^{*}$ & $1.47 / \mathrm{D}$ & $\mathrm{w} / \mathrm{w}^{*}$ \\
\hline 1 & 134 & 0.27 & 1.08 & 1.00 & 1.07 & 0.50 & 1.03 & 1.00 & 1.02 \\
\hline 2 & 134 & 0.45 & 0.96 & 1.00 & 0.95 & 0.70 & 0.97 & 1.00 & 0.97 \\
\hline 3 & 134 & 0.48 & 0.98 & 1.00 & 0.97 & 0.74 & 0.98 & 1.00 & 0.98 \\
\hline 4 & 134 & 0.62 & 1.04 & 1.00 & 1.03 & 0.90 & 1.04 & 1.00 & 1.04 \\
\hline 5 & 134 & 0.86 & 0.96 & 1.00 & 0.95 & 1.17 & 0.97 & 1.00 & 0.98 \\
\hline 6 & 134 & 0.98 & 1.02 & 1.00 & 1.01 & 1.35 & 1.00 & 1.00 & 1.01 \\
\hline 7 & 132 & 0.576 & 0.78 & 0.79 & 0.96 & 0.895 & 0.79 & 0.79 & 0.98 \\
\hline 8 & 132 & 1.193 & 0.81 & 0.79 & 1.00 & 1.653 & 0.80 & 0.79 & 1.01 \\
\hline 9 & 131 & 0.677 & 0.64 & 0.66 & 0.96 & 1.062 & 0.65 & 0.66 & 0.98 \\
\hline 10 & 131 & 1.412 & 0.67 & 0.66 & 1.00 & 1.968 & 0.67 & 0.66 & 1.01 \\
\hline 11 & 131 & 0.778 & 0.56 & 0.56 & 0.97 & 1.227 & 0.56 & 0.56 & 1.00 \\
\hline 12 & 131 & 1.632 & 0.58 & 0.56 & 1.02 & 2.284 & 0.57 & 0.56 & 1.02 \\
\hline
\end{tabular}

Table 3 shows that the $1.47 / D$ ratios for FE models 7 through 12 are close to the $w^{(D=1.47)} / w^{*}$ ratios. Therefore, to account for scale effects, Eqn. (13) was modified by multiplying it by $D / 1.47$. In addition, Eqn. (13) was modified for two ranges of $D / t_{w}$ values to improve correlation between $w$ and $w^{*}$. Splitting Eqn. (13) at $D / t_{w}=164$ with different slope and y-intercept terms derived for each group provided the best fit. The best fit equations for the width of the tension field that crosses the compression diagonal, in units of meters, is therefore: 


$$
\begin{array}{rlrl}
w & =\left(\left(0.315 \ln \left(\frac{D}{t_{w}}\right)-1.306\right)\left(\frac{a}{D}\right)+0.647 \ln \left(\frac{D}{t_{w}}\right)-3.209\right) \times D & & D / t_{w} \leq 164 \\
& =\left(\left(0.278 \ln \left(\frac{D}{t_{w}}\right)-1.124\right)\left(\frac{a}{D}\right)+0.376 \ln \left(\frac{D}{t_{w}}\right)-1.792\right) \times D & & 164<D / t_{w} \\
w & =\left(\left(0.278 \ln \left(\frac{D}{t_{w}}\right)-1.072\right)\left(\frac{a}{D}\right)+0.622 \ln \left(\frac{D}{t_{w}}\right)-2.99\right) \times D & & D / t_{w} \leq 164 \\
& =\left(\left(0.31 \ln \left(\frac{D}{t_{w}}\right)-1.249\right)\left(\frac{a}{D}\right)+0.238 \ln \left(\frac{D}{t_{w}}\right)-0.992\right) \times D & 164<D / t_{w}
\end{array}
$$

Eqns. (14) and (15) are for $\sigma_{y}=250 \mathrm{MPa}$ and $345 \mathrm{MPa}$, respectively.

This formulation, therefore, considers scale, slenderness, aspect ratio, and material. Table 3 shows that Eqns. (14) and (15) for $w$ correlate well to the predictions given by the FE solution, typically coming within $5 \%$ of $w^{*}$. This good correlation is not surprising since $w$ is derived from FE results. The next section examines the "physical" correlation of $w$ to FE results (i.e., the observed width of the tension field in the FE models). But since $w$ is useful only for deriving $V_{u}$, the true validation of $w$ will be based on how well $V_{u}$ correlates to both FE and experimental results. These validations will be done in the sections that follow.

\subsection{Validation of the Compression-Based Model}

\section{1. $w$ versus $F E$ observation of tension field}

Figures $14(\mathrm{a})$ and (b) show 2 representative FE models $(a / D=1.0$ and 2.0$)$ with $D / t_{w}=134$ and $\sigma_{y}=250 \mathrm{MPa}$. A dashed black diagonal line is drawn on each plate representing the equivalent column location. The contour plots of the maximum in-plane principal stresses are drawn for $V=V_{u}$, where the red zone marks the region of highest tensile stresses. Superimposed to scale on 
this contour is the width, $w$, based on Eqns. (14) and (15). It is seen that these equations predict reasonably well the width of the tension field that forms.

Figures 14(c) and (d) plot the out-of-plane displacements at $V_{u}$ measured along the diagonal dashed line. It is seen that the peak out-of-plane displacements occur approximately at the center of the diagonal lines. Also superimposed in Figures 14(c) and (d) is the predicted width, w, drawn to scale. The plots show that this width develops in the regions of maximum displacement.

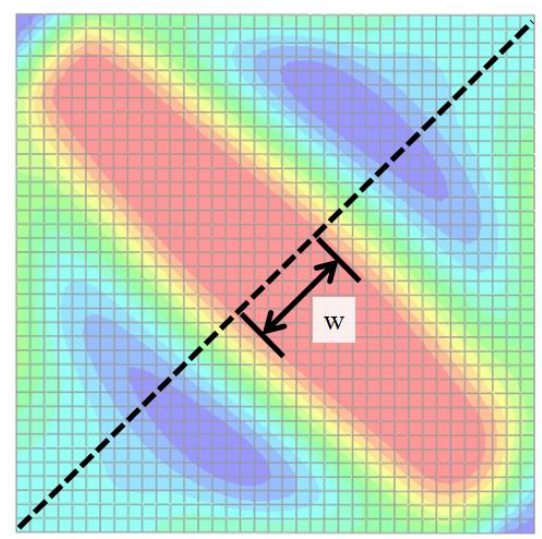

(a)

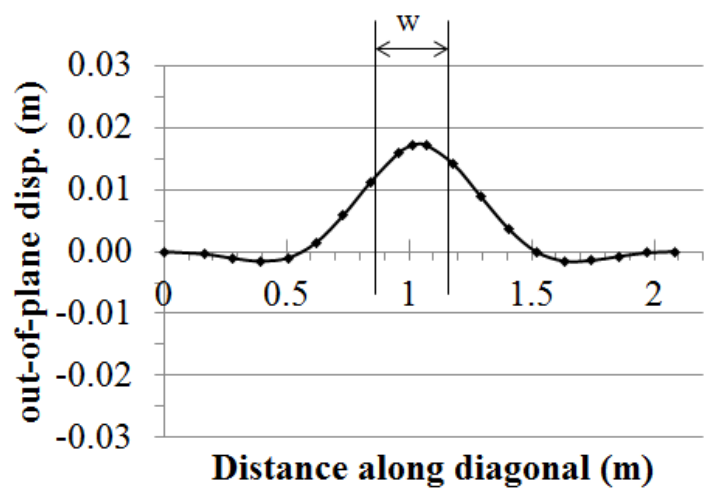

(c)

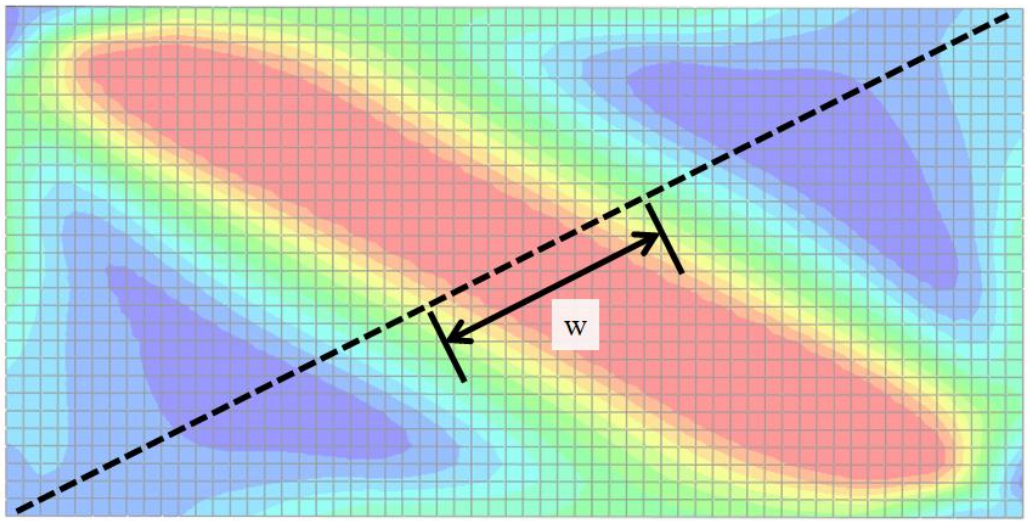

(b)

Figure 14. Contour plot of the maximum in-plane principal stresses at $V_{u}$ for $a / D$ of (a) 1.0 and (b) 2.0, with a black dashed diagonal line indicating the assumed location of the equivalent column. Plots (c) and (d) show the out-ofplane displacements measured along this diagonal line from the bottom left corner to the top right corner for $a / D=1.0$ and 2.0, respectively. Superimposed in these figures is the predicted width, $w$, drawn to scale based on Eqns. (14) and (15). 
For $a / D=3.0$, the physical response of the plate changes compared to $a / D=1.0$ and 2.0. Two $D / t_{w}$ ratios are examined in Figure 15 for $a / D=3.0: D / t_{w}=134$ and 294. These two ratios represent the spectrum of stress contour plots for $a / D=3$.0. Figures 15 (a) and (b) show contour plots of the maximum in-plane principal stresses at $V_{u}$ for plates with $a / D=3.0, \sigma_{y}=250 \mathrm{MPa}$, and $D / t_{w}$ of (a) 134 and (b) 294. The out-of-plane displacements at $V_{u}$ measured along the black dashed diagonal lines are shown in Figure 15(c) and (d) for $D / t_{w}$ of 134 and 294, respectively. Superimposed in Figures 15(a) through (d) is the width, $w$, drawn to scale based on Eqns. (14) and (15).

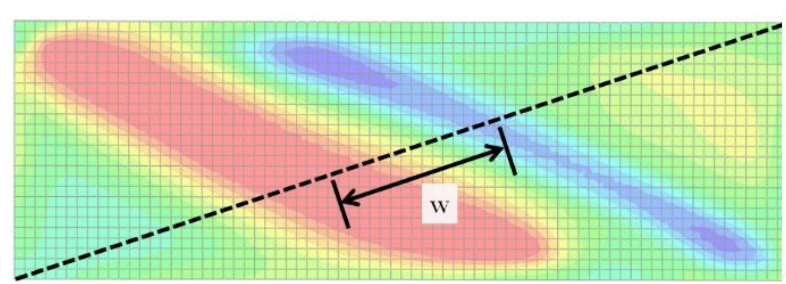

(a)

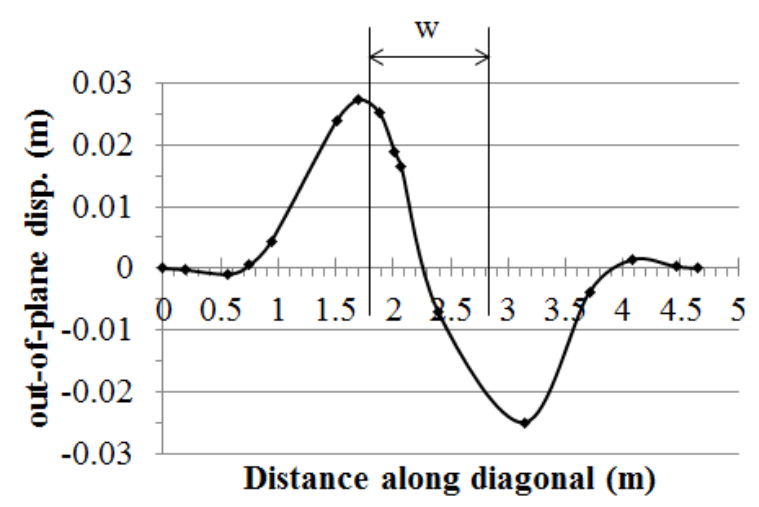

(c)

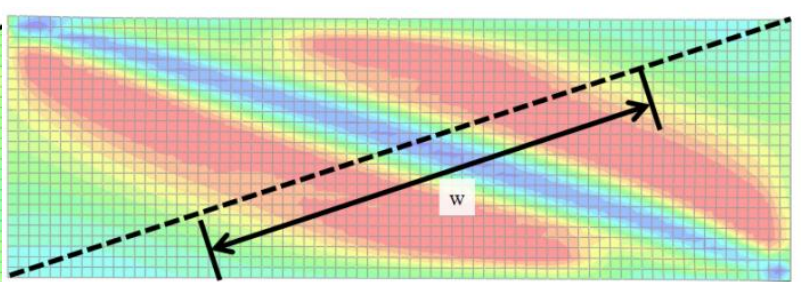

(b)

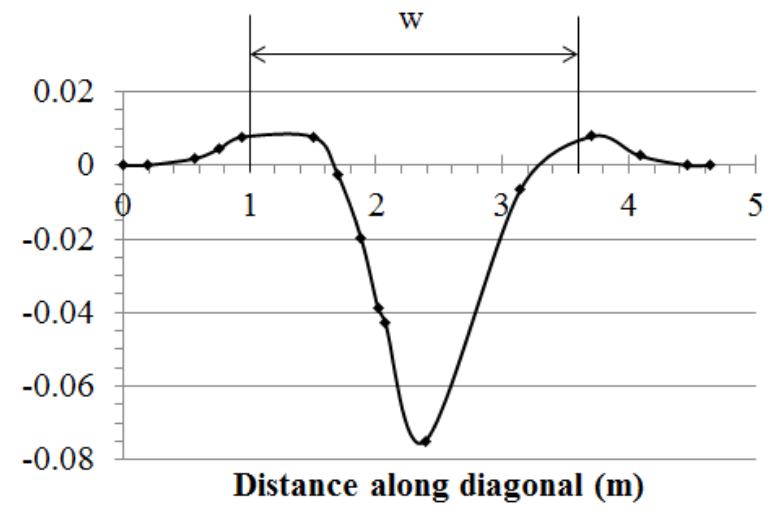

(d)

Figure 15. Contour plot of the maximum in-plane principal stresses at $V_{u}$ for $a / D$ of 3.0 and $D / t_{w}$ of (a) 134 and (b) 294, with a black dashed diagonal line indicating the assumed location of the equivalent column. Plots (c) and (d) show the out-of-plane displacement measured along this diagonal line from the bottom left corner to the top right corner for $D / t_{w}=134$ and 294, respectively. Superimposed in these figures is the predicted width, $w$, drawn to scale based on Eqns. (14) and (15).

From Figures 15(a) and (c), which show results for $D / t_{w}=134$, it is seen that $w$ is centered approximately about the inflection point between the peak and trough of the out-of-plane displacements. From Figures 15 (b) and (d), however, which show results for $D / t_{w}=294$, it is seen that $w$ captures the width of the two tension fields that form. Eqns. (14) and (15) calculate a 
larger $w$ value as $D / t_{w}$ increases, which is consistent with what is observed in Figure 15 . Despite the tension field being slightly off-center from the diagonal for smaller $D / t_{w}$ values (see Figure 15(a)), it will be shown in the next section that assuming $w$ is centered at the mid-length of the compression diagonal will still result in an accurate prediction of $V_{u}$ using the compression approach for $a / D=3.0$.

\subsection{Comparison of $V_{u}$ to finite elements}

Using Eqns. (14) and (15), $w$ is solved for from which $L_{e}=L-w$. This value of $L_{e}$ is then used in Eqn. (10) to solve for $V_{u}$ assuming $Q_{v}=1.0$. Figures 16 and 17 and Table 4 compare $V_{u}{ }^{F E}$ (the finite element solution) to both $V_{u}$ (derived based on Eqns. (10), (14), and (15) - the compression approach) and $V_{u}{ }^{B T}$ (the $\underline{B}$ asler-Thürlimann solution from Eqn. (1)). Models 1 through 6 (with $D$ $=1.47 \mathrm{~m}$ ) are presented in Figures 16 and 17, and Models 7 through 12 (with larger $D$ values) are presented in Table 4 . In both figures, the dashed red lines mark the 5\% correlation values.

It is seen in Figures 16(a) and 17(a) that $V_{u}$ based on the compression approach is generally within $5 \%$ of $V_{u}^{F E}$, and always within $10 \%$ of $V_{u}^{F E}$, except for 2 data points. Comparison to Basler in Figures 16(b) and 17(b) shows, however, that the $V_{u}{ }^{B T}$ values do not correlate as well to $V_{u}^{F E}$. As slenderness increases, $V_{u}^{B T} / V_{u}^{F E}$ generally becomes smaller, reaching values as low as 0.63 for $a / D=3.0, D / t_{w}=294$, and $\sigma_{y}=345 \mathrm{MPa}$ (Figure 17(b)). These trends illustrated in Figures 16 and 17 for Models 1 through 6 are also seen in Table 4 for Models 7 through 12. 

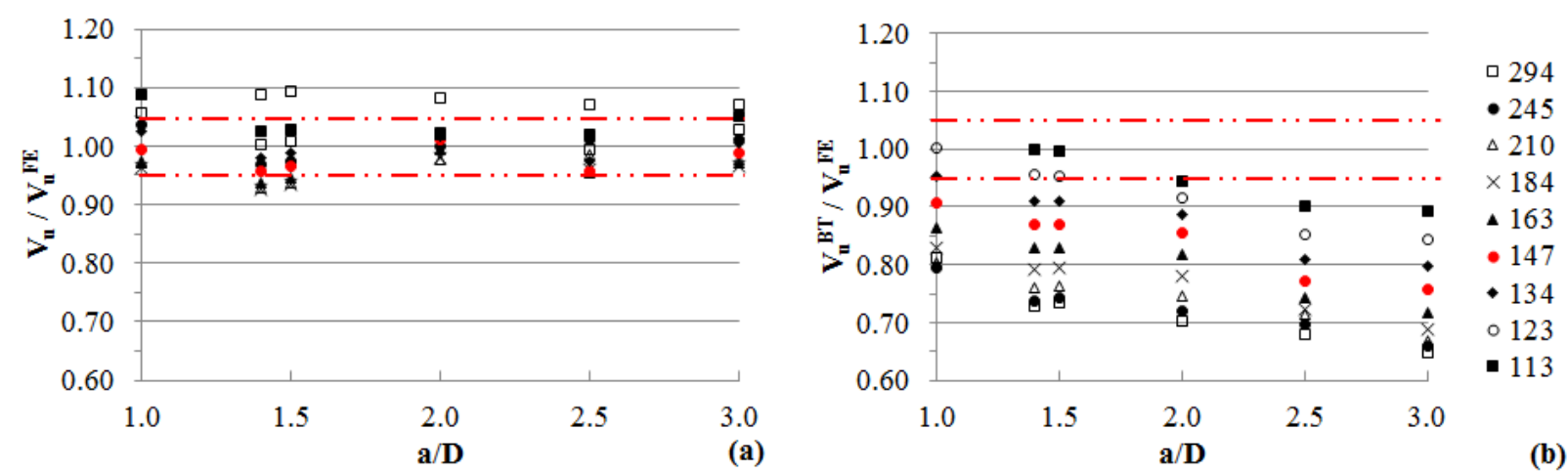

Figure 16. Comparison of (a) $V_{u}$ (compression approach - Eqn. (10)) and $V_{u}^{F E}$ and (b) $V_{u}{ }^{B T}$ and $V_{u}{ }^{F E}$ for FE models 1 through 6 and for $\sigma_{y}=250 \mathrm{MPa}$.
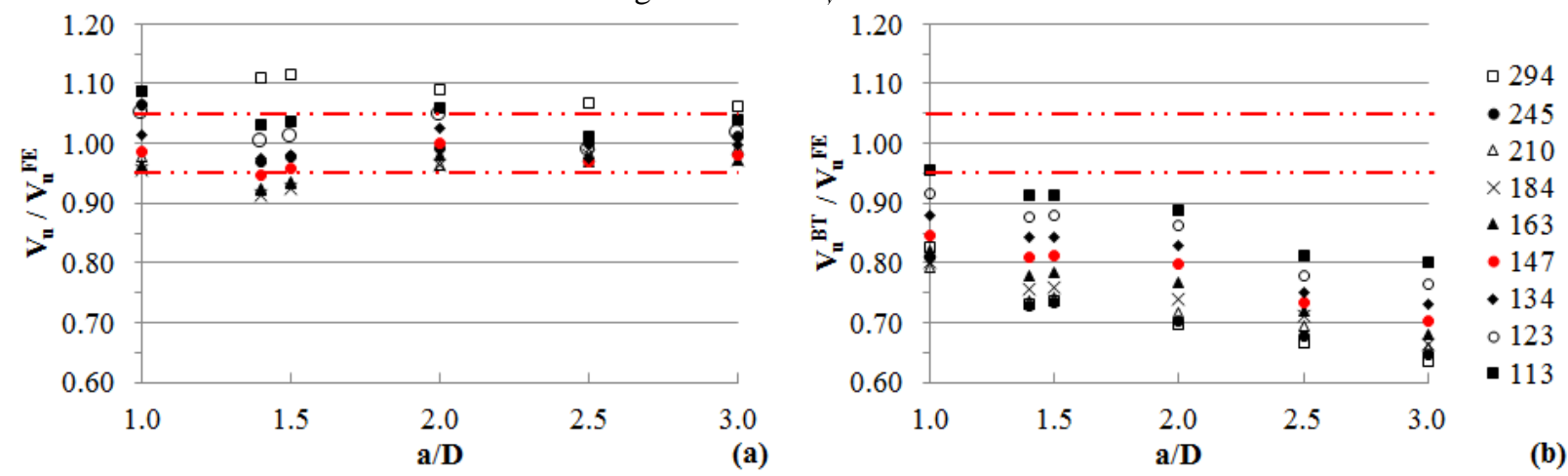

Figure 17. Comparison of (a) $V_{u}$ (compression approach - Eqn. (10)) and $V_{u}{ }^{F E}$ and (b) $V_{u}{ }^{B T}$ and $V_{u}{ }^{F E}$ for FE models 1 through 6 and for $\sigma_{y}=345 \mathrm{MPa}$.

Table 4. Comparison of $V_{u}$ and $V_{u}^{B T}$ for FE models 7 through 12.

\begin{tabular}{|c|c|c|c|c|}
\hline \multirow{2}{*}{ FE Model } & \multicolumn{2}{|c|}{$\sigma_{y}=250 \mathrm{MPa}$} & \multicolumn{2}{c|}{$\sigma_{y}=345 \mathrm{MPa}$} \\
\cline { 2 - 5 } & $V_{u} / V_{u}{ }^{F E}$ & $V_{u}{ }^{B T} / V_{u}{ }^{F E}$ & $V_{u} / V_{u}{ }^{F E}$ & $V_{u}{ }^{B T} / V_{u}{ }^{F E}$ \\
\hline 7 & 0.99 & 0.92 & 0.99 & 0.85 \\
\hline 8 & 1.01 & 0.81 & 1.01 & 0.74 \\
\hline 9 & 0.99 & 0.92 & 0.99 & 0.86 \\
10 & 1.01 & 0.81 & 1.01 & 0.75 \\
\hline 11 & 0.99 & 0.92 & 0.99 & 0.86 \\
\hline 12 & 1.01 & 0.81 & 1.01 & 0.75 \\
\hline
\end{tabular}

\subsection{Comparison of $V_{u}$ to experimental results}

This section evaluates how the compression approach for predicting $V_{u}$ compares with published experimental data [17, 32]. Experimental $V_{u}$ results $\left(V_{u}{ }^{E x p}\right)$ were compared with values using the compression approach $\left(V_{u}\right)$ calculated from Eqns. (10), (14), and (15) assuming $Q_{v}=1.0$. Eleven specimens were removed from the data in $[17,32]$ since these had $D / t_{w}$ values equal to 800 ,

which would not be used in the design of plate girders used in bridges and buildings (the focus of 
this study). With these removed, in total 84 specimens were compared with $V_{u}$. To enable detailed evaluation, these 84 specimens were separated into two sets:

- Set A specimens (27 total) fall within the most common geometric and material parameter range for plate girders used in bridges and buildings. In addition, this set falls within the range of finite element model parameters used to calibrate the compression model. The range of parameters for Set A are thus: $180 \mathrm{MPa} \leq \sigma_{y} \leq 420 \mathrm{MPa} ; 100 \leq D / t_{w}$ $\leq 300 ; 1.0 \leq a / D \leq 3.0 ;$ and $t_{f} t_{w} \leq 5$. This data set is shown in Table 5 .

- Set B specimens (57 total) have geometric parameters $\left(a / D, D / t_{w}, t_{f} / t_{w}\right)$ and the material parameter $\left(\sigma_{y}\right)$ that fall beyond that of Set A, such as $D / t_{w}>300$ or $\sigma_{y}>420 \mathrm{MPa}$.

Note that Equations (14) and (15), from which $V_{u}$ is based, are derived for two discrete values of $\sigma_{y}: 250 \mathrm{MPa}$ and $345 \mathrm{MPa}$. However, most of the specimens studied (e.g., see Table 5) have different yield stresses. To enable direct comparison with experimental results, a linear interpolation and extrapolation of Eqns. (14) and (15) was done. Figure 18 presents the results of this interpolation and extrapolation for Set A. It is seen that the $V_{u} / V_{u}^{E x p}$ values typically fall within 0.90 and 1.10 (as marked in the shaded region), regardless if an interpolation or extrapolation was done. One outlier does exist (corresponding to specimen G8-T2 [32]), however this specimen appears to have been re-tested (specimen G8-T3 [32]), which resulted in a $V_{u} / V_{u}^{E x p}$ value close to 1.00 . These results indicate that interpolation and extrapolation may be used to calculate $w$ within the range $180 \mathrm{MPa} \leq \sigma_{y} \leq 420 \mathrm{MPa}$. Extrapolation, however, does not work well for yield stresses outside of this range as will be shown later when Set B is discussed.

Table 5 presents the results of Set A in more detail. Again, it is seen that the $V_{u}$ and $V_{u}^{E x p}$ values agree well, and generally within $10 \%$ (based on the $V_{u} / V_{u}^{E x p}$ column) for all 27 specimens of this Set. Table 5 also compares the experimental results with the $\underline{B} a$ sler-Thürlimann solution 
from Eqn. (1). Two values are presented: $V_{u}{ }^{B T-F L}$ calculates the $k$ value in Eqn. (2) considering the flange thickness, while $V_{u}{ }^{B T-S S}$ calculates this $k$ value assuming simple supports for the flanges per Eqn. (3). Both the $V_{u}{ }^{B T-F L} / V_{u}{ }^{F E}$ and $V_{u}{ }^{B T-S S} / V_{u}{ }^{F E}$ values are generally less than 1.00 and in some cases offer predictions that are less than $70 \%$ of $V_{u}{ }^{E x p}$.

Table 5. Set A specimens: comparison of compression approach, Basler (tension) approach, and experimental data from $[17,32]$.

\begin{tabular}{|c|c|c|c|c|c|c|c|c|c|c|c|c|}
\hline \multirow[b]{2}{*}{ Specimen } & \multicolumn{5}{|c|}{ Experimental } & \multicolumn{2}{|c|}{ Compression approach } & \multirow{2}{*}{\multicolumn{2}{|c|}{$\begin{array}{c}\text { Basler approach } \\
\mathrm{V}_{\mathrm{u}}^{\text {BT-FL }}(\mathrm{kN}) \mathrm{V}_{\mathrm{u}}^{\text {BT-SS }}(\mathrm{kN})\end{array}$}} & \multirow{2}{*}{\multicolumn{3}{|c|}{\begin{tabular}{|c|}
$\frac{\text { Performance ratios }}{\mathrm{V}_{\mathrm{u}} / \mathrm{V}_{\mathrm{u}}^{\text {Exp }} \mathrm{V}_{\mathrm{u}}^{\mathrm{BT}-\mathrm{FL}} / \mathrm{V}_{\mathrm{u}}^{\text {Exp }} \mathrm{V}_{\mathrm{u}}^{\mathrm{BT}-\mathrm{SS}} / \mathrm{V}_{\mathrm{u}}{ }^{\text {Exp }}}$
\end{tabular}}} \\
\hline & $\mathrm{D}(\mathrm{m})$ & $\mathrm{a} / \mathrm{D}$ & $\mathrm{D} / \mathrm{t}_{\mathrm{w}}$ & $\sigma_{\mathrm{y}}(\mathrm{MPa})$ & $\mathrm{V}_{\mathrm{u}}^{\operatorname{Exp}}(\mathrm{kN})$ & $\mathrm{w}(\mathrm{m})$ & $\mathrm{V}_{\mathrm{u}}(\mathrm{kN})$ & & & & & \\
\hline$G 6-T 1^{[24]}$ & 1.270 & 1.50 & 259 & 253 & 516 & 1.180 & 533 & 428 & 393 & 1.03 & 0.83 & 0.76 \\
\hline$G 7-T 1^{[24]}$ & 1.270 & 1.00 & 255 & 253 & 623 & 0.899 & 691 & 542 & 515 & 1.11 & 0.87 & 0.83 \\
\hline$G 7-T 2^{[24]}$ & 1.270 & 1.00 & 255 & 253 & 645 & 0.899 & 691 & 542 & 515 & 1.07 & 0.84 & 0.80 \\
\hline $2.2^{[25]}$ & 0.600 & 2.40 & 300 & 255 & 75 & 0.876 & 80 & 58 & 52 & 1.06 & 0.78 & 0.70 \\
\hline$U S 3 / 5^{[26]}$ & 0.359 & 2.19 & 133 & 257 & 90 & 0.168 & 99 & 108 & 84 & 1.10 & 1.21 & 0.94 \\
\hline $\mathrm{STG} 1^{[27]}$ & 0.279 & 1.97 & 140 & 255 & 60 & 0.134 & 56 & 60 & 48 & 0.94 & 1.00 & 0.80 \\
\hline$S-3^{[30]}$ & 0.477 & 1.21 & 149 & 317 & 198 & 0.191 & 189.9 & 199 & 176 & 0.96 & 1.01 & 0.89 \\
\hline $\mathrm{STG} 2^{[27]}$ & 0.253 & 2.0 & 158 & 272 & 40 & 0.174 & 41.0 & 39 & 32 & 1.03 & 0.96 & 0.79 \\
\hline $\mathrm{RTG}^{[27]}$ & 0.254 & 1.00 & 267 & 259 & 24 & 0.190 & 26.9 & 21 & 20 & 1.12 & 0.86 & 0.82 \\
\hline TG5 $5^{[33]}$ & 1.000 & 1.00 & 400 & 200 & 308 & 0.981 & 295.7 & 151 & 146 & 0.96 & 0.49 & 0.47 \\
\hline TG5-1 ${ }^{[33]}$ & 1.000 & 1.00 & 400 & 200 & 300 & 0.981 & 295.7 & 151 & 146 & 0.99 & 0.50 & 0.49 \\
\hline $\mathrm{U} 2 / 5^{[26]}$ & 0.359 & 2.19 & 113 & 230 & 135 & 0.074 & 124.2 & 144 & 117 & 0.92 & 1.06 & 0.86 \\
\hline $\mathrm{TG} 22^{[27]}$ & 0.305 & 1.00 & 150 & 229 & 79 & 0.084 & 75.0 & 72 & 64 & 0.95 & 0.91 & 0.82 \\
\hline $\mathrm{TG} 23^{[27]}$ & 0.305 & 1.00 & 150 & 229 & 81 & 0.084 & 75.0 & 72 & 64 & 0.93 & 0.89 & 0.80 \\
\hline TGV $1-1^{[34]}$ & 0.600 & 2.00 & 290 & 211 & 83 & 0.714 & 81.3 & 60 & 54 & 0.98 & 0.72 & 0.65 \\
\hline TGV $1-2^{[34]}$ & 0.600 & 1.00 & 290 & 211 & 111 & 0.457 & 123.0 & 87 & 83 & 1.11 & 0.79 & 0.75 \\
\hline TGV2-2 $2^{[34]}$ & 0.600 & 1.00 & 288 & 211 & 115 & 0.455 & 123.5 & 88 & 84 & 1.07 & 0.77 & 0.73 \\
\hline TGV3-2 $2^{[34]}$ & 0.600 & 1.00 & 299 & 211 & 113 & 0.469 & 120.0 & 84 & 80 & 1.06 & 0.74 & 0.71 \\
\hline LS1-PA ${ }^{[35]}$ & 0.608 & 1.55 & 290 & 183 & 76 & 0.587 & 81.1 & 63 & 57 & 1.07 & 0.82 & 0.75 \\
\hline LS3-PA ${ }^{[35]}$ & 0.608 & 1.56 & 247 & 201 & 103 & 0.519 & 104.9 & 87 & 78 & 1.02 & 0.84 & 0.76 \\
\hline$R T G 1^{[27]}$ & 0.305 & 1.00 & 240 & 244 & 40 & 0.202 & 42.2 & 33 & 31 & 1.05 & 0.83 & 0.79 \\
\hline$R T G 2^{[27]}$ & 0.305 & 1.00 & 240 & 244 & 41 & 0.202 & 42.2 & 33 & 31 & 1.03 & 0.81 & 0.77 \\
\hline$C P 1 / 1^{[29]}$ & 0.500 & 1.49 & 245 & 246 & 88 & 0.439 & 87.7 & 71 & 65 & 1.00 & 0.81 & 0.74 \\
\hline$S-2^{[30]}$ & 0.319 & 1.82 & 100 & 352 & 161 & 0.085 & 167.9 & 190 & 152 & 1.04 & 1.18 & 0.95 \\
\hline$G 8-T 1^{[24]}$ & 1.270 & 3.00 & 250 & 263 & 375 & 1.960 & 432.4 & 323 & 275 & 1.15 & 0.86 & 0.73 \\
\hline$G 8-T 2^{[24]}$ & 1.270 & 1.50 & 250 & 263 & 445 & 1.164 & 576.8 & 466 & 426 & 1.30 & 1.05 & 0.96 \\
\hline$G 8-T 3^{[24]}$ & 1.270 & 1.50 & 250 & 263 & 516 & 1.164 & 576.8 & 466 & 426 & 1.12 & 0.90 & 0.83 \\
\hline
\end{tabular}

Notes: 1. Italicized specimens were also used for the FE model validation results presented in Table 1. 2. Superscripts [24], [25], [26], [27], [28], [29], [30], [33], [34], [35] are references to publications. 


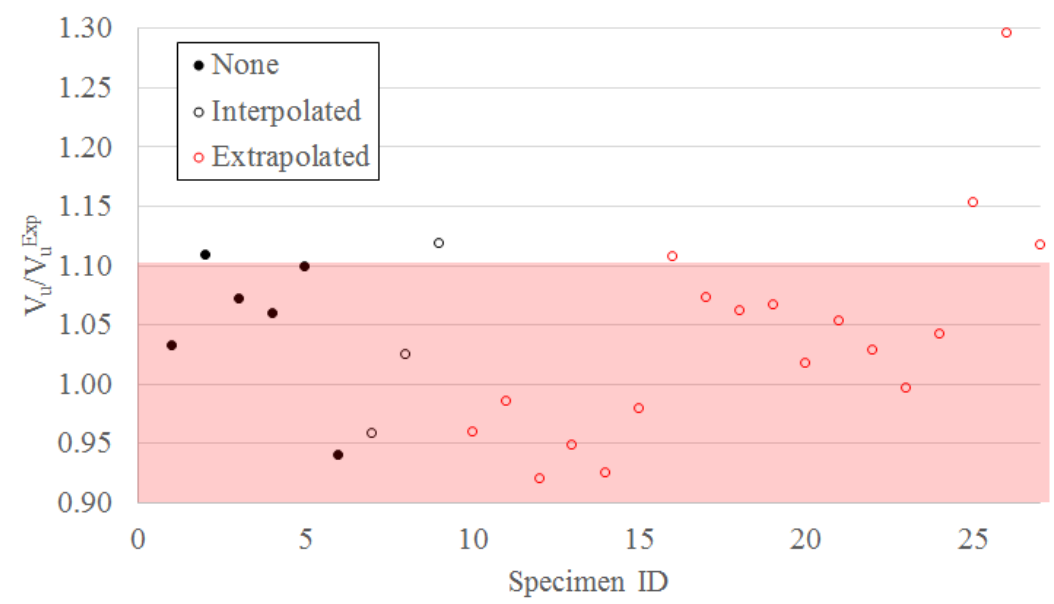

Figure 18. Plot of $V_{u} / V_{u}^{E x p}$ values based on Set A specimens (Table 5). Solid black circles correspond with $V_{u}$ values where $w$ was calculated directly using Eqns. (14) and (15), while open black and red circles indicate $V_{u}$ values calculated with an interpolated or extrapolated $w$ value, respectively.

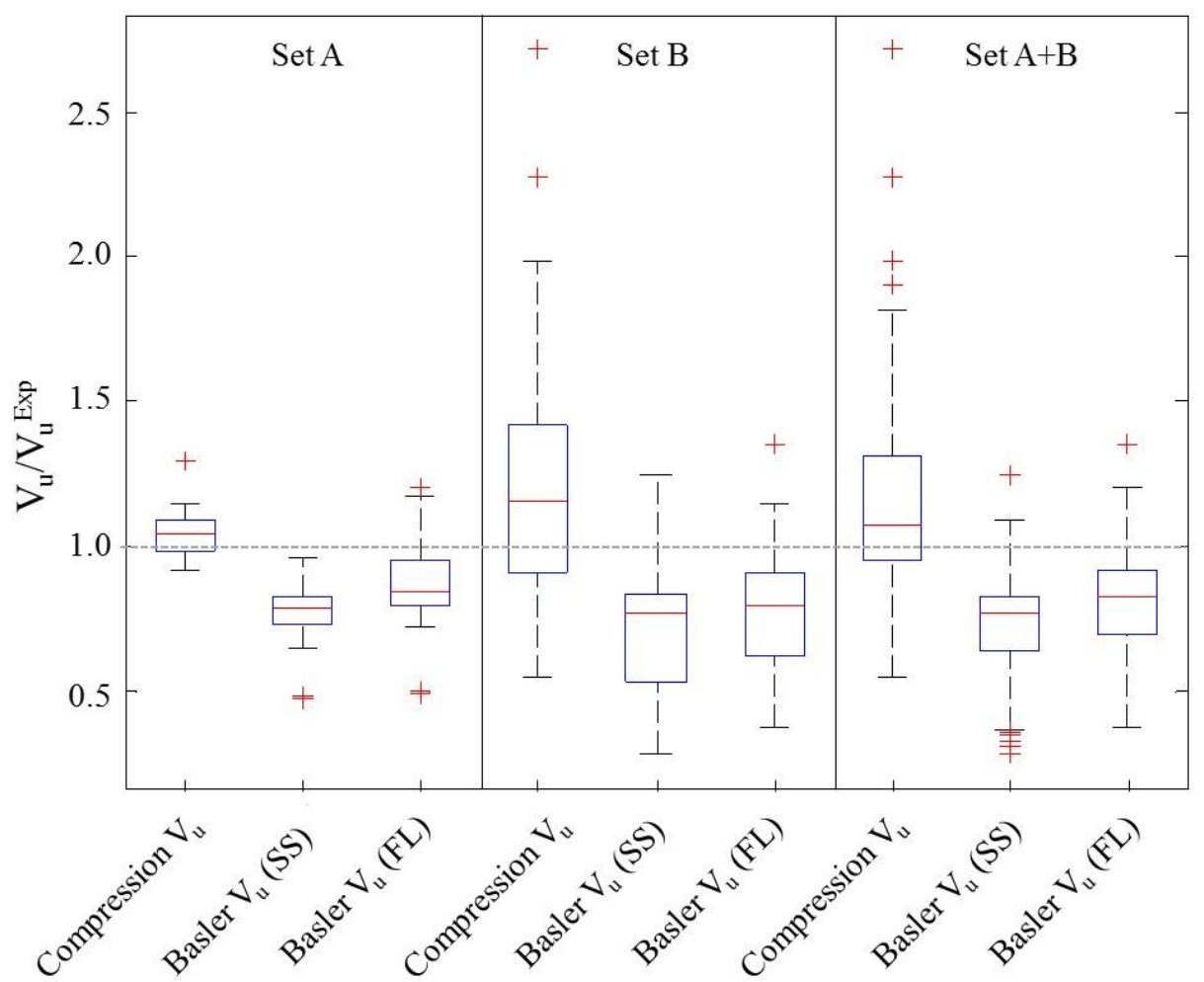

Figure 19. Box plots comparing $V_{u} / V_{u}^{E x p}$ values for Set A, B, and A+B.

A statistical comparison of the data is made through box plots shown in Figure 19. On each box, the central mark is the median (the second quartile), the edges of the box are the 25th and 75th percentiles (i.e., the first and third quartiles, Q1 and Q3). The boxes enclose the interquartile 
range (IQR). The lower whisker is a line from Q1 to the smallest $V_{u} / V_{u}^{E x p}$ within $1.5 \cdot \mathrm{IQR}$ from Q1. Similarly, the upper whisker is a line from Q3 to the largest $V_{u} / V_{u}^{E x p}$ within 1.5·IQR from Q3. Data outside of the whiskers are considered outliers and plotted individually with a cross. For each data set (A, B, and A and B combined), Figure 19 shows box plots for the compression approach (“Compression $V_{u}$ "), Basler's model calculated assuming simply supported boundary conditions for the flanges, $V_{u}{ }^{B T-S S}$ ("Basler $V_{u}(\mathrm{SS})$ "), and Basler's model calculated considering the flange thickness, $V_{u}{ }^{B T-F L}$ ("Basler $V_{u}(\mathrm{FL})$ ").

It is seen in Figure 19 that the compression $V_{u}$ in Set $\mathrm{A}$, which contains 27 specimens within a common range of geometric and material properties, has Q1 and Q3 near the median, which is close to 1.0, and short whiskers. Thus, Set A has excellent fit with the experimental data. One outlier does exist, which is the same outlier discussed with Figure 18. The "Compression $V_{u}$ " model using the geometric and material constraints defined by Set A has a better fit to the experimental data than the Basler model, regardless of the value used for $k$.

Set B data of Figure 19, which has geometric and material parameters outside that of Set A, shows that the Basler $V_{u}$ models have a better fit than the compression $V_{u}$ model, which has a large spread in the data. This figure indicates that the compression model needs to be further developed for better fit to geometric and material properties outside the geometric and material constraints defined by Set A. The two outliers for the compression approach for $V_{u}$ of Set B have $\sigma_{y}=745 \mathrm{MPa}$, which is well outside the $\sigma_{y}$ range of Set A. These results indicate that the extrapolation of yield stress is not valid for $\sigma_{y}$ outside of the range $180 \mathrm{MPa} \leq \sigma_{y} \leq 420 \mathrm{MPa}$.

When Sets A and B are combined in Figure 19, the results for the compression $V_{u}$ model are reasonable. The median is closer to the experimental results than the Basler models, however, the Basler models have a smaller IQR and shorter whiskers, thus indicating a smaller spread in the 
data - i.e., more consistent results. The four outliers for the compression approach for $V_{u}$ in this combined Set correspond to specimens with $a / D, D / t_{w}$, and $\sigma_{y}$ values that are well outside the common design parameters of Set A.

Overall, Figure 19 and Table 4 show that the compression $V_{u}$ model has excellent correlation to experimental data for the geometric and material parameters most common to plate girders used in bridges and buildings. It also has a better fit to the experimental data than the Basler solution for this data set. However, the Basler solution is more consistent in predicting $V_{u}$ for the entire data set and the predictions are conservative throughout, albeit sometimes perhaps too conservative.

\subsection{Conclusions}

Traditional approaches for calculating the ultimate postbuckling shear strength $\left(V_{u}\right)$ have relied on tension field theory, which is based on the fundamental assumption that once elastic shear buckling has occurred, the postbuckling shear strength is due solely to the development of tensile stresses within a defined diagonal tension field. Since buckling is inherently a phenomenon based on compression, this paper presented a new approach where the compressive response dominates the physical model, and the tension field plays a secondary, yet critical, role.

The mechanics of shear buckling was examined via finite element analyses with models that were experimentally validated. It was shown that the response of a plate that buckles in shear is similar to a plate that buckles under axial compression: in the postbuckling phase, tensile stresses exist perpendicular to the compressive stresses, and the compressive stress distribution is larger

on the edges than in the center for both types of loading. The results of this finite element study also disagreed with the key assumptions of tension field theory since it was found that (1) 
compressive stresses continue to increase in the postbuckling range - in particular near the edges, and (2) the stiffeners and flanges do not necessarily anchor the tension field.

An equation for predicting $V_{u}$ based on a compression model was developed, which considered scale (plate depth), plate slenderness, aspect ratio (distance between transverse stiffeners versus depth), and yield stress. The results of this compression model for $V_{u}$ were compared to finite element models and 84 experimental results. The compression model for $V_{u}$ was also compared to the solution for $V_{u}$, developed in 1961 by Basler, whose basis is the tension field approach.

Results show that the compression model for $V_{u}$ has excellent correlation to experimental data for the most common geometric and material parameters with structural engineering applications: $180 \mathrm{MPa} \leq \sigma_{y} \leq 420 \mathrm{MPa} ; 100 \leq D / t_{w} \leq 300 ; 1.0 \leq a / D \leq 3.0$; and $t_{f} / t_{w} \leq 5$. Within this range of parameters, the compression model for $V_{u}$ also has a better fit to the experimental data than the Basler solution. However, the Basler solution is more consistent in predicting $V_{u}$ for data outside of this set of parameters. Further, Basler predictions are conservative throughout, albeit sometimes too conservative.

Future work will further develop the compression model for better fit to geometric and material properties outside the geometric and material constraints defined above. This could be done via further study of the variable $Q_{v}$ in the compression model and through additional finite element studies outside of the current range of study. Further, the authors are currently studying how to incorporate the effects of elevated temperatures into the compression model.

Overall, this work shows that a compression approach to predicting $V_{u}$ is viable and leads to excellent correlation with design parameters common to plate girders used in bridges and 
buildings. Further study is encouraged for applicability to a wider range of parameters and for the development of simpler equations that can be used in design.

\section{Acknowledgments}

The authors would like to acknowledge Theodore Zoli from HNTB Corporation and Dr. Jean H. Prévost from Princeton University for their insights. This research was made with Government support under and awarded by DoD, Air Force Office of Scientific Research, National Defense Science and Engineering Graduate (NDSEG) Fellowship, 32 CFR 168a, provided to Dr.

Glassman. This research was also sponsored by the National Science Foundation (NSF) under grant CMMI-1068252. All opinions, findings, and conclusions expressed in this paper are of the authors and do not necessarily reflect the policies and views of the sponsors.

\section{References}

[1] R. D. Ziemian, Guide to Stability Design Criteria for Metal Structures, 6th ed., Hoboken: John Wiley \& Sons, 2010.

[2] D. W. White and M. G. Barker, "Shear Resistance of Transversely Stiffened Steel I-Girders," Journal of Structural Engineering, vol. 134, no. 9, pp. 1425-1436, 2008.

[3] C. H. Yoo and S. C. Lee, "Mechanics of Web Panel Postbuckling Behavior in Shear," Journal of Structural Engineering, vol. 132, no. 1, pp. 1580-1589, 2006.

[4] K. Basler, "Strength of Plate Girders in Shear," Trans. ASCE, vol. 128, no. 2, 1961.

[5] H. Wagner, "'Flat Sheet Metal Girder with Very Thin Metal Web", Tech. Notes. 604, 605, 606," National Advisory Committee on Aeronautics, Washington, DC, 1931.

[6] S. Lee, J. Davidson and C. Yoo, "Shear Buckling Coefficients of Plate Girder Web Panels," Computers and Structures, vol. 59, no. 5, pp. 789-795, 1996.

[7] S. C. Lee and C. H. Yoo, "Strength of Plate Girder Web Panels Under Pure Shear," Journal of Structural Engineering, vol. 124, no. 2, pp. 184-194, 1998.

[8] K. N. Rahal and J. E. Harding, "Transversely stiffened girder webs subjected to shear loading - part 1: behaviour," Proceedings of the Institution of Civil Engineers, vol. 89, no. 2, pp. 47-65, 1990.

[9] K. N. Rahal and J. E. Harding, "Transversely stiffened girder webs subjected to shear loading - part 2: stiffener design," Proceedings of the Institution of Civil Engineers, vol. 89, no. 2, pp. 67-87, 1990.

[10] M. E. M. Garlock and J. D. Glassman, "Elevated temperature evaluation of an existing analytical model for steel web shear buckling," Journal of Constructional Steel Research, vol. 101, pp. 395-406, 2014, doi:10.1016/j.jcsr.2014.05.021.

[11] C. Marsh, W. Ajam and H.-K. Ha, "Finite Element Analysis of Postbuckled Shear Webs," Journal of Structural Engineering, vol. 114, no. 7, pp. 1571-1587, 1988.

[12] J. M. Wilson, "On Specifications for Strength of Iron Bridges," Trans. ASCE, vol. 15, no. Part I, pp. 401-403, 
489-490, 1886.

[13] J. D. Glassman and M. E. M. Garlock, "High temperatures and bridges: transverse stiffeners in steel girder fire performance," in 7th New York City Bridge Conference, New York, 2013.

[14] American Institute of Steel Construction, Steel Construction Manual 14th edition, 2011.

[15] American Association of State Highway and Transportation Officials, "AASHTO LRFD Bridge Design Specifications (6th Edition)," 2012. [Online]. Available: http://www.knovel.com/knovel2/Toc.jsp?BookID=4852. [Accessed 13 February 2013].

[16] D. M. Porter, K. C. Rockey and H. R. Evans, "The Collapse Behavior of Plate Girders Loaded in Shear," Struct. Eng., vol. 53, no. 8, pp. 313-325, 1975.

[17] A. S. Elamary, "Ultimate Shear Resistance of Plate Girders Part 2 - Hoglund Theory," International Journal of Civil, Architectural, Structural and Construction Engineering, vol. 7, no. 12, pp. 580-588, 2013.

[18] T. Höglund, "Shear Buckling Resistance of Steel and Aluminum Plate Girders," Thin-Walled Structures, vol. 29, pp. 13-30, 1997.

[19] E. H. Gaylord, "Discussion of K. Basler 'Strength of Plate Girders in Shear'," Trans. ASCE, vol. 128, no. Part II, p. 712, 1963.

[20] T. Fujii, "On an Improved Theory for Dr. Basler's Theory," in IABSE 8th Congr., Final Rep., New York, 1968.

[21] A. Selberg, "On the Shear Capacity of Girder Webs," Univ. Trondheim Rep., 1973.

[22] S. P. Timoshenko and J. M. Gere, Theory of Elastic Stability, Second Edition, New York: McGraw-Hill Book Company, Inc., 1961.

[23] Dassault Systemes, "Abaqus 6.11ef Online Documentation," [Online]. [Accessed 2012].

[24] K. Basler, B. T. Yen and J. A. Mueller, "Web Buckling Tests on Welded Plate Girders," Welding Research Council, Bulletin No. 64 Sept., New York, 1960.

[25] A. Bergfelt and J. Hovik, "Thin-walled deep plate girders under static loads," in Proceedings of the IABSE Colloquium, New York, 1968.

[26] A. G. Kamtekar, J. B. Dwight and B. D. Threlfall, "Tests on Hybrid Plate Girders (Report 2), Report No. CUED/C-Struct/TR28," Cambridge University, Cambridge, 1972.

[27] K. C. Rockey and M. Skaloud, "The ultimate load behaviour of plate girders loaded in shear," The Structural Engineer, vol. 50, no. 1, pp. 29-48, 1972.

[28] H. R. Evans, K. C. Rockey and D. M. Porter, "Tests on longitudinally reinforced plate girders subjected to shear," in Proceedings of Conference on Structural Stability, Liege, 1977.

[29] R. Narayanan and K. C. Rockey, "Ultimate load capacity of plate girders with webs containing circular cutouts," Proceedings of the Institution of Civil Engineers, Part 2, vol. 71, pp. 845-862, 1981.

[30] F. Sakai, T. Fujii and Y. Fukuchi, "Failure Tests of Plate Girders Using Large-sided Models," University of Tokyo, Department of Civil Engineering, Structural Engineering Report, Tokyo, 1966.

[31] FHWA, Federal Highway Administration, "Standard Plans for Highway Bridges, Volume II, Structural Steel Superstructures," 1982.

[32] A. W. Davies and D. S. C. Griffith, "Shear strength of steel plate girders," Proc. Instn Civ. Engrs Structs \& Bldgs, vol. 134, pp. 147-157, 1999.

[33] M. Skaloud, "Ultimate load and failure mechanism of thin webs in shear," in Proceedings of Design of Plate and Box Girders for Ultimate Strength Colloquium, IABSE, London, 1971.

[34] K. C. Rockey, G. Valtinat and K. H. Tang, "The design of transverse stiffeners on webs loaded in shear - an ultimate load approach," Proceedings of the Institution of Civil Engineers, Part 2, vol. 71, pp. 1069-1099, 1981.

[35] H. R. Evans and K. H. Tang, "An Investigation of the Ultimate Load Behaviour of Longitudinally Stiffened Plate Girder Webs Loaded Predominantly in Shear, Report DT/SC/11, Mar.," University of Wales College of Cardiff, Cardiff, 1983. 


\section{LIST OF FIGURES}

Figure 1. Plate behavior (simply supported) under pure axial load compared to pure shear load.

Figure 2. Orientation of the diagonal tension field at $\tau_{u}$ for a plate with simple supports (SS) assumed for all four edges. $D$ is the depth of the plate, and $a$ is the span between transverse stiffeners.

Figure 3. (a) Boundary conditions imposed in the finite element model to simulate pure shear loading, where a "." indicates a restrained translational (U) or rotational (UR) degree of freedom; and stress state in an infinitesimally small element (b) before elastic buckling and (c) after elastic buckling.

Figure 4. Mesh densities for FE models 1 through 6.

Figure 5. Normal stresses in horizontal and vertical strips at $V_{u}$.

Figure 6. Normal stresses in diagonal strips at $V_{u}$.

Figure 7. Principal stresses (maximum, $\sigma_{\max }$, and minimum, $\sigma_{\min }$ ) plotted along the tension field (corner to corner) for $a / D=2.0, D / t_{w}=147$, and $\sigma_{y}=250 \mathrm{MPa}$.

Figure 8. Minimum (compression) principal stresses plotted along the compression diagonal (corner to corner) for $a / D=2.0, D / t_{w}=147$, and $\sigma_{y}=250 \mathrm{MPa}$.

Figure 9. Maximum compression stresses $\left(\sigma_{M i n}\right)$ across various cuts of the compression field for $a / D=2.0$ and $D / t_{w}=147$.

Figure 10. Angle of principal stresses at various locations for $a / D$ values of (a) 1.0, (b) 2.0, and (c) 3.0 at $V_{u}$; (d) diagram of tension field, centerline of equivalent column, and angle $\alpha$; (e) $\alpha$ and $\theta_{p}$ values.

Figure 11. The equivalent column model for the development of a compression approach to plate shear buckling.

Figure 12. (a) Area, $A$, over which $P_{\text {avg }}$ is calculated, (b) schematic of varying stresses acting over area $A$, and (c) notations used in Eqn. (7). 
Figure 13. Plot of $w^{*}$ versus $a / D$ for different $D / t_{w}$ values and $\sigma_{y}$ of (a) $250 \mathrm{MPa}$ and (b) $345 \mathrm{MPa}$. The linear regression results are plotted for each set of data points corresponding with (from top to bottom) $D / t_{w}$ values of $294,245,210,184,163,147,134,123$, and 113.

Figure 14. Contour plot of the maximum in-plane principal stresses at $V_{u}$ for $a / D$ of (a) 1.0 and (b) 2.0, with a black dashed diagonal line indicating the assumed location of the equivalent column. Plots (c) and (d) show the out-of-plane displacements measured along this diagonal line from the bottom left corner to the top right corner for $a / D=1.0$ and 2.0, respectively. Superimposed in these figures is the predicted width, $w$, drawn to scale based on Eqns. (14) and (15).

Figure 15. Contour plot of the maximum in-plane principal stresses at $V_{u}$ for $a / D$ of 3.0 and $D / t_{w}$ of (a) 134 and (b) 294, with a black dashed diagonal line indicating the assumed location of the equivalent column. Plots (c) and (d) show the out-of-plane displacement measured along this diagonal line from the bottom left corner to the top right corner for $D / t_{w}=134$ and 294 , respectively. Superimposed in these figures is the predicted width, $w$, drawn to scale based on Eqns. (14) and (15).

Figure 16. Comparison of (a) $V_{u}$ (compression approach - Eqn. (10)) and $V_{u}{ }^{F E}$ and (b) $V_{u}{ }^{B T}$ and $V_{u}^{F E}$ for FE models 1 through 6 and for $\sigma_{y}=250 \mathrm{MPa}$.

Figure 17. Comparison of (a) $V_{u}$ (compression approach - Eqn. (10)) and $V_{u}^{F E}$ and (b) $V_{u}{ }^{B T}$ and $V_{u}^{F E}$ for FE models 1 through 6 and for $\sigma_{y}=345 \mathrm{MPa}$.

Figure 18. Plot of $V_{u} / V_{u}^{E x p}$ values based on Set A specimens (Table 5). Solid black circles correspond with $V_{u}$ values where $w$ was calculated directly using Eqns. (14) and (15), while open black and red circles indicate $V_{u}$ values calculated with an interpolated or extrapolated $w$ value, respectively.

Figure 19. Box plots comparing $V_{u} / V_{u}^{E x p}$ values for Set A, B, and A+B. 